\title{
Abordaje para la atención clínica de la disfagia en población con diagnóstico de base neurológica en una institución de Cúcuta de Norte de Santander.
}

Approach for clinical care of dysphagia in population with neurological based diagnosis in an institution of Cucuta North of Santander.

Soto-Céspedes, Juan-Carlos*1; Rojas-Lemus, Nahomy-Sirley*2; Téllez-Torres, Gelka-Yaryt*3; Orozco-Hernandez, Ana-Milena*4; Sampayo-Rangel, Ana María*5; Lizarazo-Ortiz, Sergio-Andelfo*6.

Como citar este artículo: Soto-Céspedes, Juan-Carlos; Rojas-Lemus, Nahomy-Sirley; Téllez-Torres, Gelka-Yaryt; Orozco-Hernandez, Ana-Milena; Sampayo-Rangel, Ana María; Lizarazo-Ortiz, Sergio-Andelfo. Abordaje para la atención clínica de la disfagia en población con diagnóstico de base neurológica en una institución de Cúcuta de Norte de Santander. Revistas Signos Fónicos. 2019; 5(2):61-96.

Correspondencia autor: jua.soto@mail.udes.edu.co, (Juan Carlos Soto Céspedes)

Recibido: Junio 22, 2019.

Aprobado: Octubre 1, 2019.

\section{RESUMEN}

INTRODUCCIÓN: La investigación buscó describir el abordaje clínico de la disfagia en las fases orofaringea de la deglución a través de los procedimientos objetivos y subjetivos de evaluación. MÉTODOS: Se trata de un estudio descriptivo de corte transversal cuantitativo acompañado de un trabajo de campo con 10 usuarios realizado a través del Examen Miofuncional orofacial MBGR, Evaluación clínica de la disfagia y métodos complementarios. RESULTADOS: Se realizó una organización estructural y funcional del sistema estomatognático, mostrando las variables que proporcionaba cada usuario en apoyo de gráficas, tablas. ANÁLISIS Y DISCUSIÓN: la evaluación clínica de la disfagia comprende una serie de técnicas complementaria de naturaleza subjetiva y objetiva que proporciona una mayor aproximación y precisión al momento de determinar un diagnóstico de los desórdenes deglutorios. CONCLUSIONES Es imprescindible el uso de todos los métodos complementarios para la evaluación clínica de la disfagia

PALABRAS CLAVES: Deglución, Disfagia, Medidas antropométricas,método de evaluación, Miofuncional pensamiento, gamificación.

1*Fonoaudiólogo, Especialización Practica Pedagógica Universitaria, jua.soto@mail.udes.edu.co, Orcid: 0000-0003-2095-9123, Universidad de Santander, Colombia.

2*Practicante de Fonoaudiología, rojasnahomy8@gmail.com, Orcid: 0000-0003-0414-1858, Colombia. 3*Practicante de Fonoaudiología, gelka_95@hotmail.com, Orcid:0000-0002-8858-3911, Colombia. 4^Practicante de Fonoaudiología, amohp19@gmail.com, Orcid: 0000-0002-8858-3412, Colombia. 5^Practicante de Fonoaudiología, anasampayo1397@gmail.com, Orcid: 0000-0002-4359-6196, Colombia.

6Practicante de Fonoaudiología, sergio.fonoaudiologia@gmail.com, Orcid: 0000-0002-3588-7479, Colombia. 


\section{ABSTRACT}

INTRODUCTION: The research sought to describe the clinical approach to dysphagia in the oropharyngeal phases of swallowing through objective and subjective evaluation procedures. METHODS: This is a descriptive quantitative cross-sectional study accompanied by a field work with 10 users carried out through the MBGR orofacial Myofunctional Exam, Clinical Evaluation of Dysphagia and Complementary Methods. RESULTS: A structural and functional organization of the stomatognathic system was carried out, showing the variables that each user provided in support of graphs, tables. ANALYSIS AND DISCUSSION: the clinical evaluation of dysphagia includes a series of complementary techniques of subjective and objective nature that provides a greater approximation and precision when determining a diagnosis of swallowing disorders CONCLUSIONS: The use of all complementary methods for the clinical evaluation of dysphagia is essential.

KEYWORDS: Swallowing, Dysphagia, Anthropometric measurements, evaluation method, Myofunctional

\section{INTRODUCCIÓN}

El presente estudio muestra la importancia de la evaluación clínica de la disfagia para la población con diagnóstico de origen neurológico, donde se evidencia la afectación de la biomecánica de la deglución y las funciones estomatognáticas.(1) Es importante resaltar la trascendencia del proceso deglutorio, cuya función consiste en transportar sustancias sólidas, liquidas y saliva desde la cavidad oral hasta el estómago. Este proceso se lleva a cabo por medio de fuerzas, movimientos y presiones pertenecientes al complejo orofaringolaringeo. Esta actividad neuromuscular es el resultado de una serie de movimientos coordinados por el sistema nervioso central y periférico que producen el reflejo disparador deglutorio RDD con el paso del bolo alimenticio por las región de pilares palatinos el cual consiste en la contracción de los músculos faríngeo y los que proyectan la lengua hacia atrás en el proceso de eyección.(2)(3) Este proceso consta con la participación de 5 válvulas (Labios, velo lingual, velo faríngeo, cierre de vestíbulo laríngeo (descenso de epiglotis y cuerdas vocales) y EES (Esfínter esofágico superior) que tienen como función el hermetismo de las vías aéreas, el paso seguro del alimento a fase esofágica con movimientos de apertura y cierre proporcionando eficacia en el aspecto nutricional del individuo. La deglución se encuentra segmentanda en cinco fases principales: anticipatoria, oral preparatoria, oral, faríngea y esofágica. Estas fases están reguladas por un sistema de válvulas que se abren y cierran de manera eficaz para llevar acabo la nutrición.(4)(5) Si se pierde la coordinación, el sincronismo y la eficacia en alguna de las fases anteriormente expuestas, se presenta la disfagia, caracterizada como un síntoma y no como una patología independiente que se manifiesta en diversas enfermedades, con mayor predominio en aquellas que tienen base neurológica y generalmente alterando la fase orofaringea de la deglución.(6)(7) Los estudios epidemiológicos revelan que las patologías con mayor incidencia de disfagia son: parálisis cerebral infantil entre el $58 \%$ al $90 \%$, presentando compromiso de fase oral y faríngea, se reporta incidencia de un $4,5 \%$ en trauma craneoencefálico, la que asciende a un $68 \%$ a $76 \%$ en trauma craneoencefálico grave, entre el $27 \%$ al $50 \%$ accidente cerebro vascular unilateral como bilateral con riesgo a discapacidad grave o muerte, el riesgo de disfagia en pacientes con esclerosis múltiple aumenta a medida que la enfermedad progresa con un $65 \%$, enfermedad con Parkinson y riesgo de aspiración 15\% a 56\% ,y aspiración silente entre el 15\% a 33\% que al Se denomina aspiración al ingreso del material orofaringeo por de debajo del plano glótico y al ser sintomáticas no puede ser detectadas clínicamente, lo que dificultad el diagnóstico temprano y su prevención. (8)

Para el restablecimiento de las alteraciones funcionales de la musculatura implicada en el sistema orofacial existe la terapia miofuncional, cuyo objetivo es: prevenir, evaluar, diagnosticar, educar, y rehabilitar el desequilibro muscular del sistema orofacial cuya etiología puede ser diversa (anatómica, funcional o neurológica), Esta puede ser tanto de tipo activo, donde se da la participación voluntaria del paciente y de tipo inactivo, sin participación del mismo. (9)

La evaluación miofuncional orofacial representa una etapa fundamental en el proceso de diagnóstico fonoaudiológico, posibilitando la comprensión de las condiciones anatómofuncionales del sistema estomatognático y en específico aquellas que intervienen en la deglución, por esto la importancia de contar en nuestros consultorios o escenarios de práctica clínica con un instrumento de evaluación de naturaleza objetivo - subjetivo como el protocolo de evaluación Miofuncional Orofacial MBGR que mida el estado de las estructuras y los procesos implicados en la función deglutoria y proporciona al terapeuta una perspectiva medible de cada una de las funciones estomatognáticas determinando las posibles alteraciones y características de cada usuario; permitiendo mayor seguridad en el momento de determinar una impresión diagnostica en ausencia de estudios objetivos como videofluoroscopia o videoendoscopia. 
Además la exploración anatómica y funcional dentro de este protocolo evalúa tanto los órganos principales como las funciones primarias y secundarias de dicho sistema como lo es el tono muscular, medidas faciales, examen extraoral e intraoral, sensibilidad, reflejos, modo de nutrición, deglución, entre otras. (10)Para un abordaje holístico para la atención clínica de la disfagia se debe cumplir rigurosamente con unas etapas que complemente y ayude a la evaluación de la deglución, entre ellas está la antropometría facial; se refiere al estudio de las medidas y proporciones de la cara de las personas, la cual es útil en diversas áreas para la evaluación de anomalías congénitas y deformidades adquiridas, esta evaluación clínica es de gran importancia para el diagnóstico y plan de tratamiento de cada paciente. Actualmente, la antropometría facial se utiliza para el diagnóstico y seguimiento de los diversos tratamientos médicos y áreas relacionadas. El uso de algunas mediciones antropométricas faciales está indicado durante la evaluación fonoaudiológica(11) como lo es en la terapia Miofuncional. Con el transcurrir de la historia, el hombre ha ido evolucionando y preguntándose acerca de sus propias características como ser humano. Es necesario tener en cuenta que los individuos poseemos distintos componentes estructurales del Sistema Estomatognático, los cuales en lo posible deben encontrarse en armonía a medida que vayan desarrollándose, este equilibrio depende de distintos factores, ya sean ambientales o genéticos, todos forman parte importante para que el individuo pueda desenvolverse adecuadamente.(12) Es sabido que existe una correlación entre algunas alteraciones en la postura de la cabeza, la columna del individuo, hábitos parafuncionales, etc., que pueden llegar a afectar en cierto grado, el crecimiento y desarrollo del aparato craneomandibular Ricketts propone la realización de una Cefalometría Estática para identificar la morfología craneofacial del paciente y así definir el biotipo facial del individuo, el cual posibilita junto con otros datos del mismo, sugerir un plan básico de tratamiento,(13) es decir una planificación más minuciosa y precisa del trabajo que realizaremos, así como al finalizar el tratamiento brindándonos una evaluación del progreso logrado determinado gracias al diagnóstico radiográfico que nos proporcionarán cinco características analizadas del tercio inferior del cráneo, haciendo posible la clasificación en dólicofacial, mesofacial y braquifacial del paciente. Dichas características más conocidas como el Cefalograma Resumido de Ricketts son específicamente: el eje facial, la profundidad facial, el ángulo del plano mandibular, la altura facial inferior y el arco mandibular. (14)Para realizar una valoración más profunda y enriquecer el proceso investigativo se utiliza el análisis Pont - Korkhaus el cual es un procedimiento ejecutado en la evaluación de modelos dentarios en relación al aspecto métrico del crecimiento de determinadas estructuras, que tiene como propósito determinar el ancho ideal de las regiones premolares y molares, haciendo uso además de una medición perpendicular que va desde un punto claro de los dos incisivos superiores a un punto medio de la línea proximal.(15) La utilización de este análisis permite aclarar la función determinante en la evaluación objetiva de la deglución, pues ayuda en la observación estructural de la cavidad intraoral, identificándose particularidades específicas de esta cavidad las cuales pueden ser de gran incidencia en la disfunción del proceso deglutorio. Previo a este análisis, los usuarios han sido diagnosticados a través del protocolo MBGR. Aunque el análisis Pont y Korkhaus es un método utilizado principalmente en la odontología, se quiso revisar en este estudio su valor de uso clínico para los fonoaudiólogos que se dedican principalmente al área de motricidad orofacial, a fin de determinar el crecimiento del maxilar y la profundidad del paladar, teniendo como referencia los valores determinados por Pont y Korkhaus, complementando la evaluación Miofuncional de forma objetiva.(16) Cabe resaltar que este proceso se realizó con un profesional de la odontología que tomó las impresiones dentarias y posteriormente el equipo de fonoaudiólogos realizó el análisis de las arcadas dentarias y las características de crecimiento maxilar en cada grupo de la población objeto.

La evaluación clínica de la disfagia considera el estado general y afecciones de base, el estado neurológico, la fuerza, sensibilidad y movilidad de las estructuras de cabeza y cuello, la capacidad de toser, fonar, y los cambios observados al deglutir distintos volúmenes y viscosidades.(17) Esta evaluación es considerada un procedimiento útil para identificar las áreas de disfunción, permitiendo reconocer los pacientes con posibles aspiraciones por medio de la observación de conductas que pueden inferir en la habilidad deglutoria, incluyendo la cantidad y velocidad de ingestión, además tiene en cuenta el estado de conciencia, la frecuencia respiratoria al deglutir, la salivación, el selle labial, los reflejos, la función lingual, limpieza del bolo, función del velo de paladar, sensibilidad laríngea, las etapas preparatoria oral, etapa oral, etapa faríngea , etapa faríngea y respuesta faríngea, así como la evaluación de los nervios craneales, la percepción de la cavidad oral y evaluación de los movimientos orales nutritivos (con líquido, alimento pastoso, semisólido y sólido). De igual forma deben realizarse procesos de inspección, palpación y auscultación de las estructuras del sistema digestivo y respiratorio superior, rostro y cuello, más la revisión neurológica de cabeza y cuello.(18) El examen físico posee mayor capacidad de identificar signos de disfagia orofaringea, es necesario estar atentos a signos de parálisis bulbar, compromiso de pares craneanos, disartria, disfonía, ptosis palpebral, adenopatías, atrofia lingual, asimetría facial, debilidad muscular, alteraciones de la sensibilidad cutánea y sensibilidad sensorial gustativa, infecciones que limiten la masticación, problemas en la formación del bolo y tránsito faríngeo, y presencia de signos sistémicos relacionados 
Para la realización de esta exploración clínica de la disfagia es importante tener en cuenta la oximetría de pulso como una prueba complementaria debido a que sus resultados dan la posibilidad de compromiso respiratorio o la posibilidad de que haya una aspiración laringotraqueal, esta medición no invasiva de la saturación de oxígeno periférico 2 ( SpO 2) funciona mediante el examen transcutáneo del espectro de color de la hemoglobina, que cambia con el grado de saturación, midiéndose continuamente por el oxímetro de pulso, la cual es medida por un sensor ya sea en el dedo o en el lóbulo de la oreja. Las saturaciones son generalmente precisan entre $100 \%$ y $80 \%$, encontrando factores que pueden interferir con la medición de la presión arterial de oxígeno, como una perfusión periférica pobre, uñas pintadas o manchadas por la nicotina, las orejas perforadas, contraste intravenoso medio o colorantes inyectados.(19) Este proceso permite establecer una relación entre el nivel de saturación de oxígeno y una posible aspiración durante la ingesta de alimentos, debido a que la succión frontal, hay una disminución en el nivel de saturación de oxígeno.

Así mismo para llevar a cabo la medición del grado de el que se encuentra la disfagia se utiliza la escala FOIS (Functional Oral Intake Scale), ya que puede ser una herramienta útil con la cual documentar el cambio clínico, siendo apropiada como medida independiente de la ingesta oral funcional en estudios prospectivos de la disfagia ofreciendo una visión rápida, global y funcional de la severidad de la disfagia. Además se considera una herramienta de gran utilidad en la evaluación y clasificación de pacientes que necesitan cuidados paliativos, ya que no implica una carga sobre el paciente.

En gran parte de la literatura la deglución es considerada dentro de otros aspectos anatomo-funcionales como acto neuromuscular complejo donde participa el sistema nervioso central SNC y el sistema nervioso periférico SNP , de ahí la necesidad de involucrar la evaluación funcional de nervios craneales con el fin de conocer el desempeño del componente neuromuscular adscrito al proceso deglutorio. En este examen permite realizar una inspección de las estructuras que intervienen de manera activa en la deglución a través de una serie de maniobras que proporcionan estímulos en diferentes partes de la región orofacial con el objetivo de obtener un perfil del paciente bajo las modalidades sensitivas y motoras descritas en la evaluación clínica de los nervios craneales propuesta por Wilson Pauwels Akesson - Stewart \& Sapacey acerca de cómo se encuentran las aferencias y eferencias del aparato deglutorio e identificar posibles alteraciones en alguno de sus componentes.

Si bien dentro de la evaluación clínica de la disfagia encontramos la evaluación de nervios craneales, se opta por realizar una prueba más profunda que abarcara las rutas sensitivas y motoras involucradas en el proceso deglutorio que permitirán un grado de especificidad en el momento de identificar que estructura en términos neuromusculares se encuentran falentes u puede pueda convertirse potencialmente en un factor de riesgo para la aparición de disfagia, síntoma de alta prevalencia en diversos diagnósticos presentados en nuestra población estudio. (20)

Uno de los métodos emergentes de mayor uso para la evaluación de los trastornos de la deglución es la auscultación cervical (CA), es una técnica no invasiva y económica. Este procedimiento requiere de la utilización de un estetoscopio que será ubicado en la región lateral de la unión laríngea y la tráquea en posición anterior a la arteria carótida con el fin de detectar sonidos acústicos producidos al tragar y caracterizar su comportamiento.

Surge entonces la fuerza inmanente de la pregunta de investigación: ¿Cuál es el abordaje para la atención clínica de la disfagia en población con diagnóstico de base neurológica en una institución de Cúcuta de Norte de Santander?

\section{MÉTODOS}

Esta investigación es de tipo descriptivo de corte transversal cuantitativo acompañado de un trabajo de campo en el cual se tenía una disposición de 10 usuarios de una institución de Cúcuta Norte de Santander para poder valorar a los usuarios se requieren los siguientes criterios de inclusión y exclusión.

\section{Criterios de Inclusión}

1. Pacientes pertenecientes a una institución de Cúcuta, Norte de Santander.

2. Participantes con autorización mediante Consentimiento Informado por parte de la directora de la institución.

3. Pacientes con Diagnóstico médico de base neurológica

\section{Criterios de Exclusión}


1. Pacientes que no pertenezcan a la Institución de Cúcuta, Norte de Santander.

2. Participantes sin autorización mediante consentimiento informado.

3. Pacientes sin Diagnóstico médico de base neurológica.

4. Pacientes con diagnostico psiquiátricos especialmente esquizofrenia, trastornos de comportamiento y conducta

Después de aplicado todos los criterios de inclusión y exclusión se determinó una población de 10 Usuarios identificados con diagnóstico de base neurológica.

\section{Instrumentos}

1. Examen Miofuncional Orofacial - MBGR: El protocolo permite la evaluación de las función y estructuras estomagtonaticas diseñado por las doctoras: Genaro KF, Berretin-Felix, Rehder MIBC, Marchesan IQ validado en el año 2009. Este contiene la observación de la postura, el análisis morfológico extra - intraoral, evaluación de las funciones de movilidad, tonicidad, sensibilidad orofacial, respiración, masticación, deglución y habla, El MBGR da la opción de dar a cada apartado una calificación independiente teniendo en cuenta la normalidad y gravedad en la función o estructura evaluada. (ELIANA Y HERIBERTO)

Para realizar la evaluación se debe tener en cuenta los siguientes elementos:
a) Paquímetro
b) Alimentos en diferentes consistencias
c) Cámara Fotográfica
d) Guantes
e) Baja lenguas

\section{Antropometría facial}

Registro Fotográfico según Cattoni: Las fotografías se realizan de manera frontal y lateral, con el paciente en posición natural de la cabeza además se ubica al paciente a 20 centímetros de una pared blanca. Para esto se necesita de una cámara digital adaptada a un trípode ubicada a 50 centímetros del paciente, Estas deben ser impresas en Papel Bond y se marcan los puntos anatómicos correspondientes para determinar el biotipo facial de cada uno de los pacientes.

El plano horizontal de Frankfort es línea que se dibuja desde la parte superior del canal auditivo externo hasta el punto más inferior del borde infraorbital, los ojos del paciente deben estar en forma paralela con respecto al piso. El Trichion (Tr) es el punto en el plano mediosagital donde se inicia la línea de implantación del pelo. La Glabela $(G)$ es la zona más prominente de la frente en el plano mediosagital. El Nasion (N) depresión profunda donde se unen la piel de la frente con la raíz de la nariz. Punto Subnasal (Sn) donde termina la columela (base) y comienza el labio superior. Surco mentolabial (Si) zona más posterior entre el labio inferior y la barbilla. Pogonion ( $\mathrm{Pg}$ ) punto más prominente del tejido blando de la barbilla Mentón (Me) es el punto más bajo del tejido blando de la barbilla.

Debemos señalar que no existe un grado perfecto de simetría facial en la mayoría de las personas. La cara en el plano mediosagital se divide en cinco partes iguales, y cada una de estas partes equivale a la amplitud de un ojo, es decir, que la anchura de un ojo es la quinta parte de la cara. La altura facial se dividen en tres partes iguales, el primer tercio va desde el trichion (Tr) a la glabela (G), el tercio medio desde la (G) al punto subnasal (Sn) y desde este punto al mentón, corresponde al tercio inferior de la cara. (21)

Análisis Facial Ricketts: Es un método complejo el cual se utiliza para el análisis Cefalométrico simplificando la información del tratamiento de los datos; consta de 10 factores descriptivos agrupados en 5 ángulos: 
Ángulo Nasofrontal: Se crea en la transición de la nariz a la frente. Se forma por la línea tangente a la Glabela a Figura 10. Posición ideal de las cejas. Subunidades nasales través del nasion que se intercepta con una línea tangente del nasion al dorso nasal, este ángulo su valor fluctúa entre $115^{\circ}$ y $130^{\circ}$.

Ángulo Nasolabial: Se forma con la intersección de una línea tangente al labio superior al punto subnasal $(\mathrm{Sn})$ y de este (Sn) una tangente al punto más anterior de la columela. Este ángulo su normalidad es de $95^{\circ}$ a $100^{\circ}$.

Ángulo Nasofacial: Es la inclinación del dorso nasal con relación al plano facial, por lo que primero tenemos que hallar el Plano Facial que está determinado por una línea que une la Glabela con el Pogonion y luego se traza la tangente al dorso nasal, que se halla trazando una línea que parte de la punta del dorso de la nariz hasta el nasion, el ángulo nasofacial tiene una norma de $30^{\circ}$ a $40^{\circ}$.

Ángulo Nasomental: Describe el ángulo entre la línea tangente desde el nasion a la punta nasal con la intersección de la línea desde la punta al pogonion, Tiene una norma entre $120^{\circ}$ a $132^{\circ}$.

El Ángulo Mentocervical se halla trazando una línea perpendicular al plano horizontal de Frankfort desde la Glabela al pogonion (Plano facial anterior) y esta se va a interceptar con una línea tangencial del mentón al punto cervical (C), el rango de este ángulo fluctúa entre $80^{\circ}$ y $95^{\circ}(22)$

3. Análisis Pont Korkhaus: En este estudio el odontólogo fue el encargado de la toma de impresiones dentarias, en cuyo proceso se realizó un negativo llevando a la boca un material blando semifluido compuesto por alginato, que permite obtener una réplica exacta de las estructuras que componen la cavidad oral. Con el negativo en estado de dureza, se fabricó el modelo o positivo de la arcada en yeso a partir del cual se pudo realizar el análisis de las medidas haciendo uso de un compás de puntas secas, una regla común con medidas en milímetros y la tabla de medidas de la cavidad propuesta por Pont y Korkhaus.(4)

Tabla $\mathbf{N}^{\circ}$ 1. Índice Dentario de Korkhaus

\begin{tabular}{llll}
\hline & $4+4$ & $6+6$ & Lo \\
$\begin{array}{l}\text { SI - Ancho del Arco } \\
\text { Incisivo }\end{array}$ & $\begin{array}{l}\text { Distancia } \\
\text { Interpremolar }\end{array}$ & $\begin{array}{l}\text { Distancia } \\
\text { Interpremolar }\end{array}$ & $\begin{array}{l}\text { Longitud del Arco } \\
\text { Anterior Superior }\end{array}$ \\
\hline 27 & 32 & 41.5 & 16 \\
\hline 27.5 & 32.5 & 42.3 & 16.3 \\
\hline 28 & 33 & 43 & 16.5 \\
\hline 28.5 & 33.5 & 43.5 & 16.8 \\
\hline 29 & 34 & 44.5 & 17 \\
\hline 29.5 & 34.7 & 45.3 & 17.3 \\
\hline 30 & 35.5 & 46 & 17.5 \\
\hline 30.5 & 36 & 46.8 & 17.8 \\
\hline 31 & 36.5 & 47.5 & 18 \\
\hline 31.5 & 37 & 48.5 & 18.3 \\
\hline 32 & 37.5 & 49 & 18.5 \\
\hline 32.5 & 38.2 & 50 & 18.8 \\
\hline 33 & 39 & 51 & 19 \\
\hline 33.5 & 39.5 & 51.5 & 19.3 \\
\hline
\end{tabular}


Soto J C; Rojas N S; Téllez G Y; Orozco A M; Sampayo A M; Lizarazo S A. Revista Científica Signos Fónicos, 2019,5(2): 61-96.

\begin{tabular}{llll}
\hline 34 & 40 & 52.5 & 19.5 \\
\hline 34.5 & 40.5 & 53 & 19.8 \\
\hline 35 & 41.2 & 54 & 20 \\
\hline 35.5 & 42 & 54.5 & 20.5 \\
\hline 36 & 42.5 & 55.5 & 21 \\
\hline
\end{tabular}

Fuente: Los Autores

En la tabla 1 La primera columna, corresponde al ancho de los arcos incisivos superiores, por otro lado la segunda y tercer columna $2^{\circ}$ y $3^{\circ}$ está relacionado con la distancia de los diámetros inter-premolares e inter-molares respectivamente, las medidas de la Longitud del Arco Anterior Superior pueden ser utilizadas también para el maxilar inferior (Lu), restando a cada distancia $2 \mathrm{~mm}$ correspondiente al espesor del borde incisal superior

Los indicadores en Dentición Permanente, referidos en la tabla de Korkhaus comprenden:

(a) 4 + 4: Es la distancia del diámetro Inter-premolar superior, se toma como punto de referencia la localización del punto medio de la fisura del primer premolar de derecha a izquierda.

(b) 4 - 4: Es la distancia del diámetro Inter-premolar inferior, se toma como referencia el punto de contacto entre ambos premolares por ser este el punto que coincide con el superior en el momento de la oclusión.

(c) $6+6$ : Es la distancia del diámetro Inter-molar superior, se toma como referencia el punto más profundo de la fisura meso-bucal o fosa central del primer molar del lado derecho a la del lado izquierdo.

(d) 6 - 6: Es la distancia del diámetro Inter-molar inferior, se toma como punto de referencia la cúspide media vestibular (no mesial) punto que coincide con el superior en el momento de la oclusión.

4. Evaluación Clínica de la Disfagia: Es una exploración que nos permite detectar posibles alteraciones en los procesos de deglución en sus distintas etapas o fases desde la oral hasta faríngea, acompañada de diferentes pruebas complementarias que ayudan a dar un diagnóstico más asertivo. Esta prueba incluye examen funcional de los nervios craneales, examen sensorial y motor de la cavidad oral, auscultación cervical, evaluación de la deglución oro faríngea usando diferentes alimentos con diferentes consistencias, además de la aplicación de la oximetria de pulso, la cual es considerada una prueba complementaria de la evaluación clínica de la disfagia, permitiendo realizar un seguimiento de la saturación de la sangre durante la deglución.

Para realizar la evaluación se debe tener en cuenta los siguientes elementos:

a)Alimentos líquidos, semisólidos y sólidos

b)Fonendoscopio

c) Guantes

d)Baja lenguas

e)Tapabocas

f)Aplicadores

g)Sabores

h)Olores

i)Oximetro

5. Evaluación de Nervios Craneales bajo la escala representativa de Wilson Pauwels y autores: La evaluación de nervios craneales permite localizar topográficamente una posible lesión en el sistema nervioso, según la semiología derivada de la afectación de un determinado par

Revista Científica Signos Fónicos, 2019,5(2): 61-96. ISNN 2422-1716. 
craneal. Pese al extraordinario desarrollo de las técnicas de neuroimagen, una correcta exploración y análisis de la información obtenida en términos de neuroanatomía continúa siendo esencial en la aproximación al paciente con sintomatología neurológica. - María Luisa Calle Escobar e Ignacio Casado Naranjo Unidad de Ictus. Sección de Neurología. Hospital San Pedro de Alcántara. Cáceres.

Para realizar la evaluación se debe tener en cuenta los siguientes elementos:
a) Aplicadores
b) Baja lenguas
c) Frio
d) Calor
e) Vibrador
f) Olores
g) Sabores
h) Linterna
i) Guantes

6. Auscultación cervical (CA) se llevó a cabo a través de los parámetros planteados por el Protocolo Fonoaudiológico de Avaliação do Risco para Disfagia (PARD). Para realizar la evaluación se debe tener en cuenta los siguientes elementos:
a) Estetoscopio
b) Hoja de registro
c) Consistencia bajo las medidas requeridas

\section{RESULTADOS}

De acuerdo al proceso investigativo en el instituto determinando paso a paso los protocolo y técnicas utilizadas para la evaluación de la deglución se obtienen la siguiente información de cada uno de los protocolos aplicados; Evaluación miofuncional Orofacial MBGR, Técnica korjaj, Análisis facial, Evaluación clínica de la disfagia y Pares craneales. Con el fin de abordar de manera completa y eficaz la deglución en cada de una de sus características, fases y momentos durante la evaluación.

De acuerdo a la evaluación realizada a cada uno de los usuarios de manera holística, donde se pueden evidenciar los siguientes resultados con respeto a la aplicación. En primera instancia del protocolo MBGR; Examen miofuncional orofacial, obteniendo diferentes variables en cada uno de los usuarios del instituto. El MBGR cuenta con varios apartados donde se enfatiza en esta ocasión.

En la gráfica postura corporal se resalta la evaluación de la postura corporal donde de manera frontal se puede evidenciar los resultados de la cabeza donde se refleja con mayor número de personas en coincidir en inclinación hacia el lado derecho y en los hombros elevado el lado derecho. De manera lateral de la cabeza se observa con mayor porcentaje e igualatorio entre anteriorizada, flexión y extensión y los hombros con $50 \%$ normal y anteriorizado. 


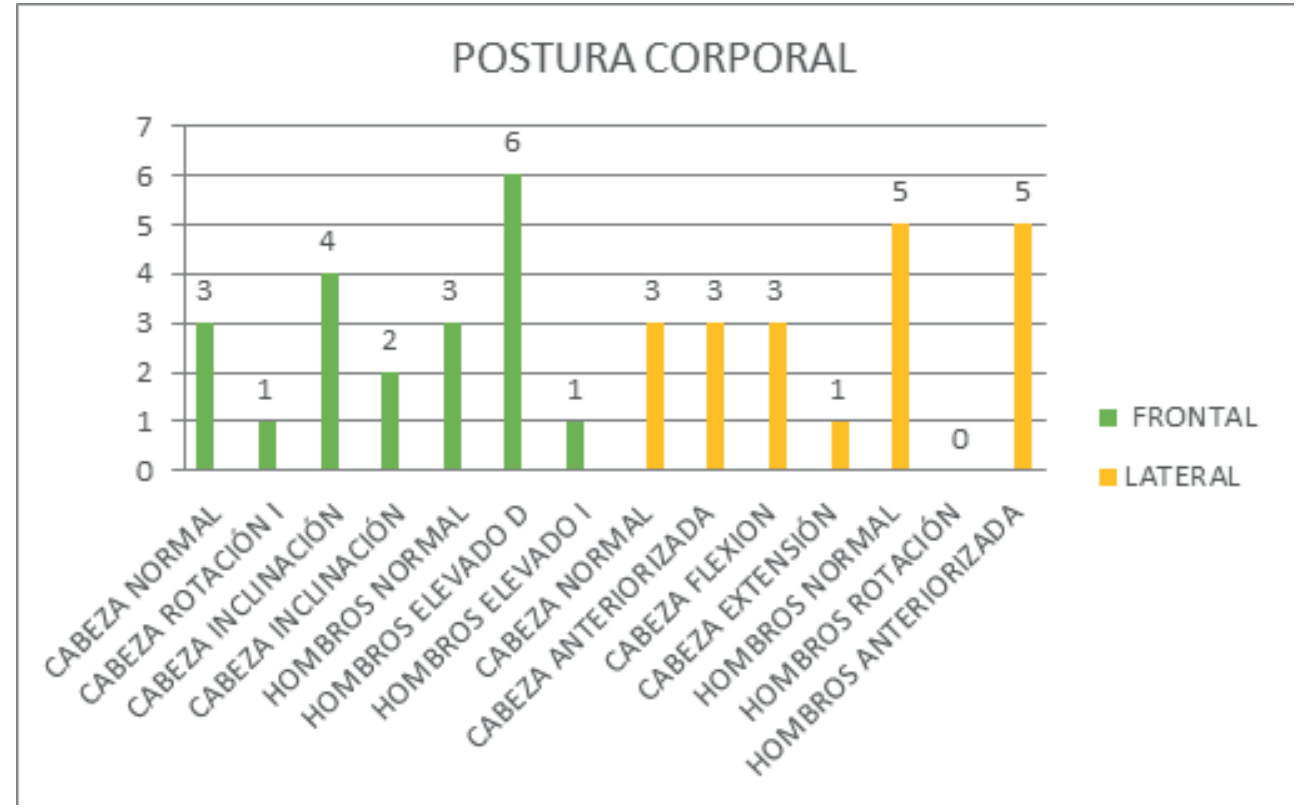

Grafica 1. Postura Corporal. Fuente: los autores

En la gráfica de medidas faciales se observa el promedio general por cada una de las medidas tomadas 3 veces en cada usuario. Se obtiene un promedio y luego de esto un promedio de toda la población de la muestra en la aplicación del protocolo MBGR

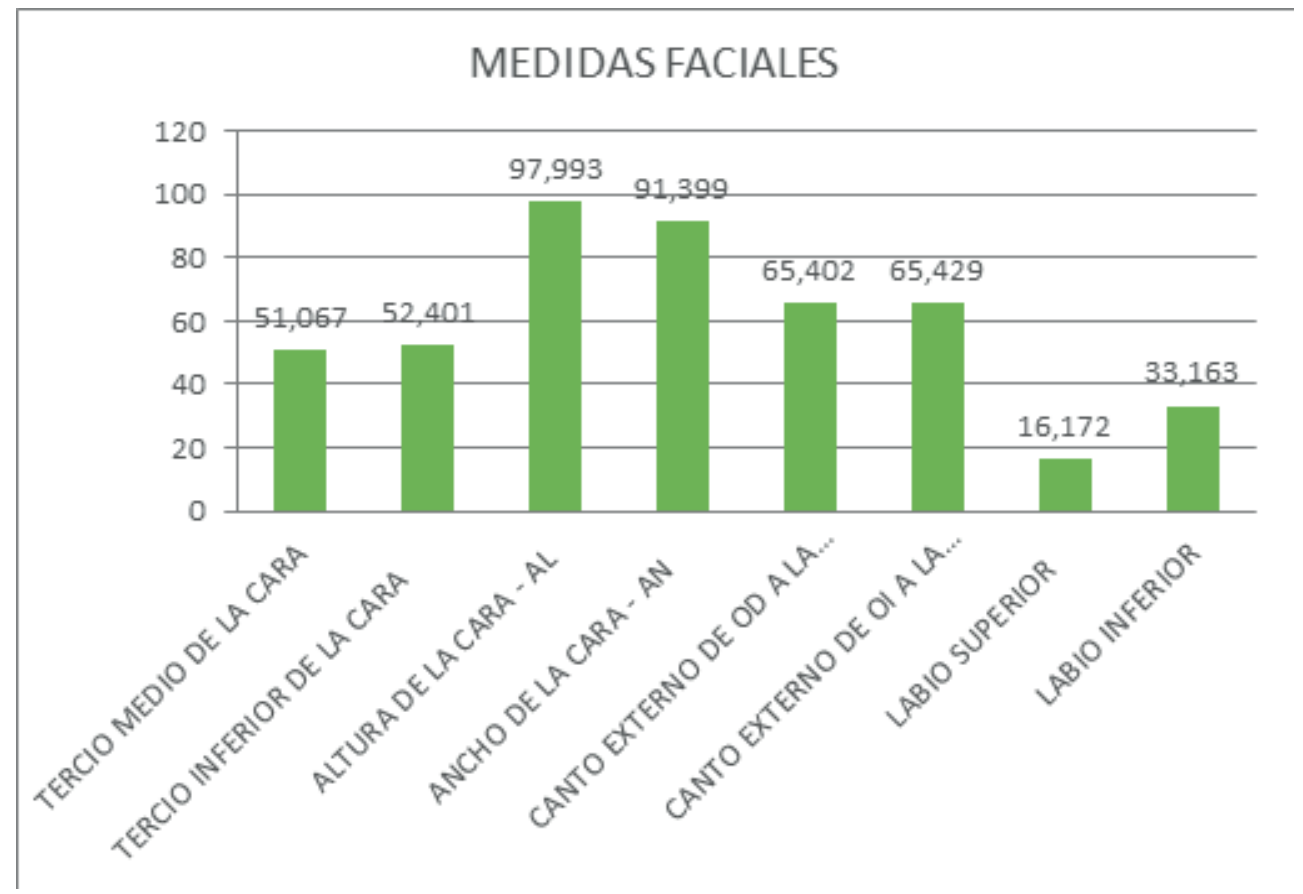

Grafico 2. Medidas faciales. Fuente: Los autores

En la gráfica de examen extraoral pueden evidenciar las diferentes características de acuerda a cada estructura miofuncional, obteniendo como resultados más altos; donde comparando las medidas tomadas el resultados del tipo facial con mayor porcentaje es largo, proporción facial: tercio inferior mayor, los cantos presentan un 50\% en simetría, cóncavo en su mayoría, el Angulo naso labial en su mayoría son próximo a $90^{\circ} \mathrm{O} 110^{\circ}$. En cuanto a los labios la postura habitual cerrados y a veces abiertos o cerrados, la mucosa externa en parámetros de normalidad, en forma el labio superior normal y el inferior con $50 \%$ de normalidad, el tamaño cubre los incisivos y el masetero donde se encuentran más pacientes con los músculos relajados y el reclutamiento lo realizan hacia el lado derecho. 


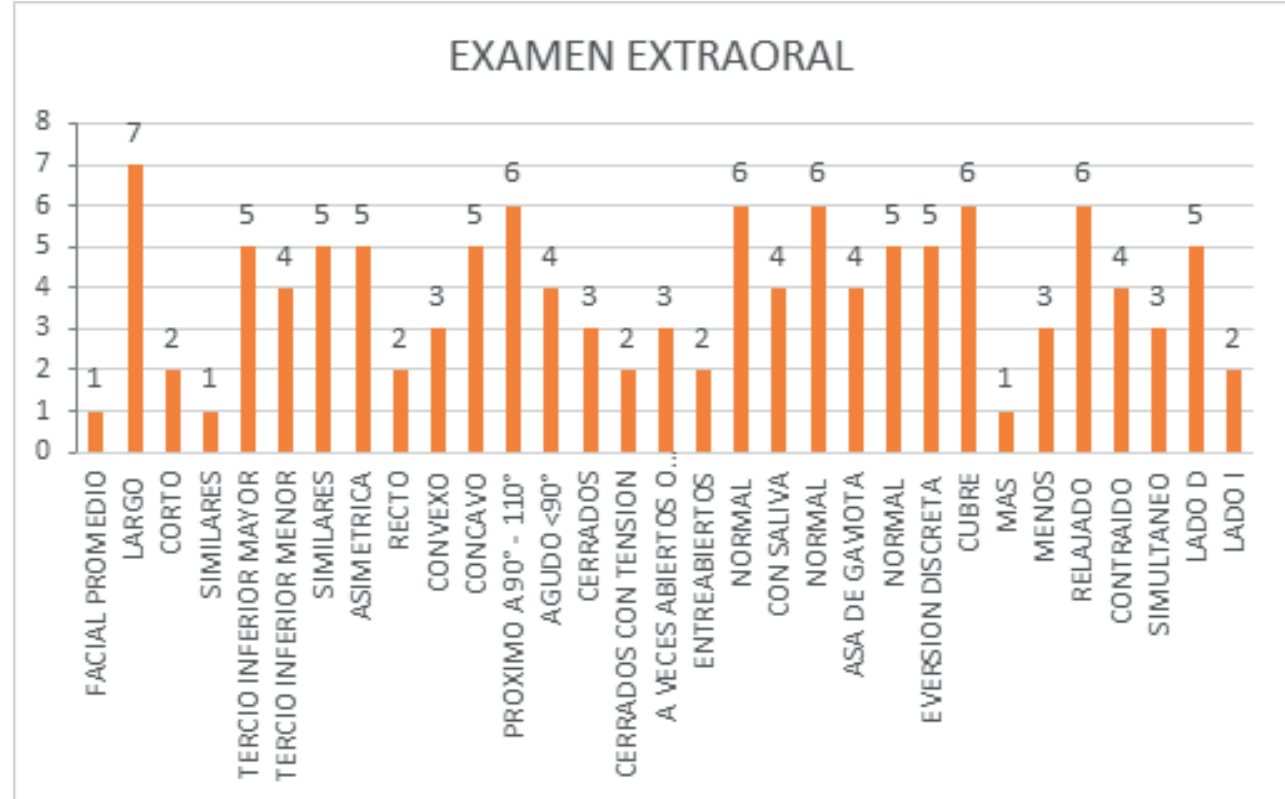

Grafico 3. Examen Extraoral. Fuente: Los autores

En la gráfica de examen intraoral se resalta la evaluación intraoral; comenzando por piezas dentarias donde se determina que la mayoría de pacientes tienen dentición permanente, además presenta ausencia de piezas dentarias en un promedio de 5 a 8 piezas, el paladar presenta un $50 \%$ de la población tiene el paladar corto y de igual manera el restante presenta un paladar largo, el 100\% de la población presenta una simetría adecuada y extensión en $80 \%$, las mejillas presenta u alto porcentaje con marcas de dientes en la mucosa, el frenillo lingual tiene un alto porcentaje la fijación en las carúnculas, la lengua el ancho es adecuado de acuerdo a la cavidad oral y los labios presentan $30 \%$ marcas de dientes y el $70 \%$ Normal. 


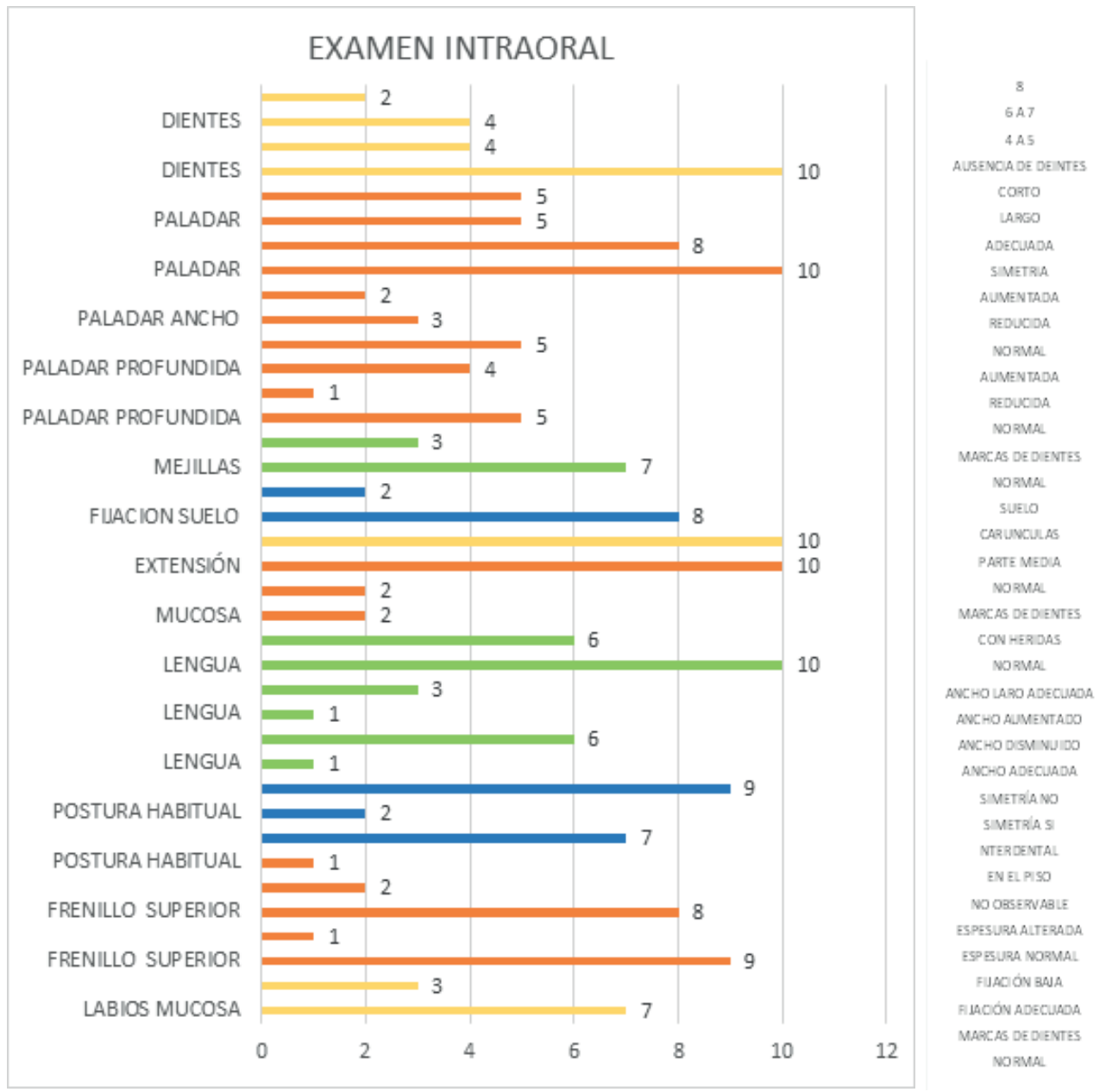

\section{Grafico 4. Examen intraoral. Fuente: Los autores}

En la gráfica de movilidad se observan las diferentes acciones que debían realizar cada usuario de acuerdo a las estructuras como lo son: labios, Lengua, paladar blando y mandíbula de acuerdo a esto de determina un gran porcentaje de los usuarios no realizan los movimientos pero esto se debe al estado de conciencia y cognición de los usuarios para realizar ordenes sencillas o imitación, en segundo lugar se encuentra el realizar la acción pero sin precisión, es decir los usuarios intentar llevar a cabo la tarea pero no logra por completo llegar a su complejidad

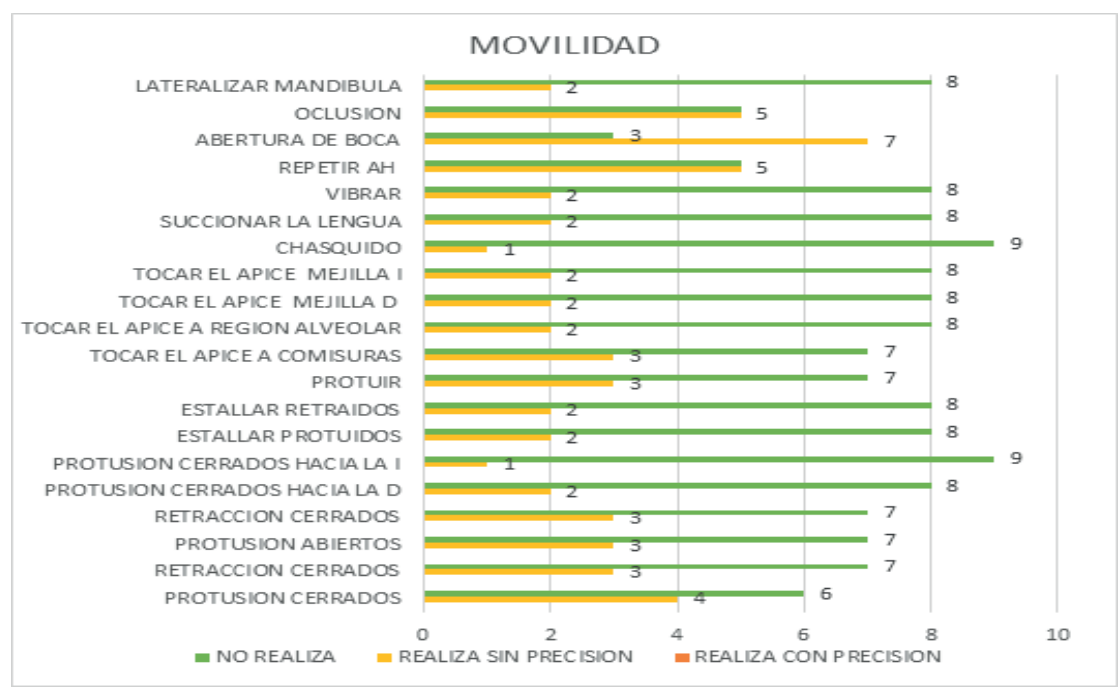


Grafico 5. Movilidad . Fuente: Los autores

En la gráfica 6, La tonicidad durante la evaluación se determina mediante la palpación de cada uno de los músculos obteniendo como resultados con unos altos porcentajes: mejilla izquierda y derecha tono muscular disminuido contando con un $60 \%$, la lengua predomina la normalidad con $50 \%$, mentón con $50 \%$ tono muscular aumentado, labio inferior y superior con $40 \%$ disminuido. Esto son los porcentajes más altos en cada una de las estructuras aunque son de suma importancia los demás valores.

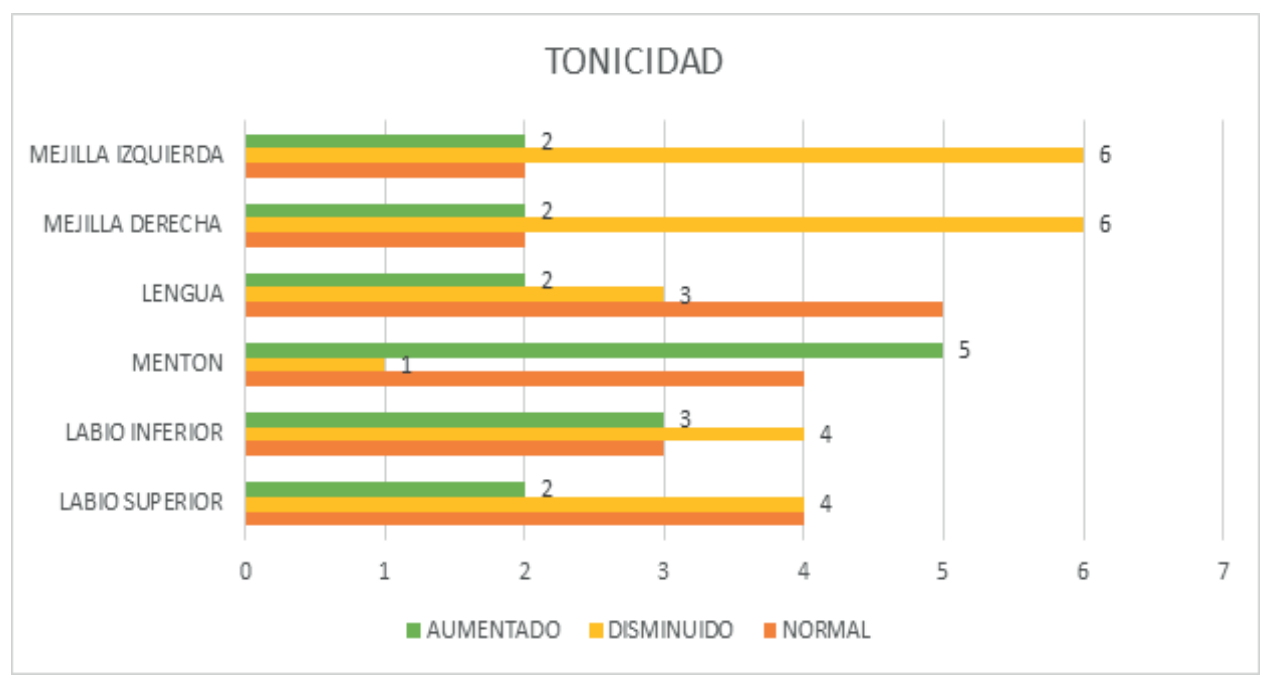

Grafico 6. Tonicidad . Fuente: Los autores

En el grafico 7, representa las características de la respiración en la población de estudio evidenciando una preferencia en el Tipo medio inferior con $60 \%$, Modo nasa, Flujo nasal entre narinas asimetría leve y la posibilidad de uso nasal entre 1 o 2 minutos.

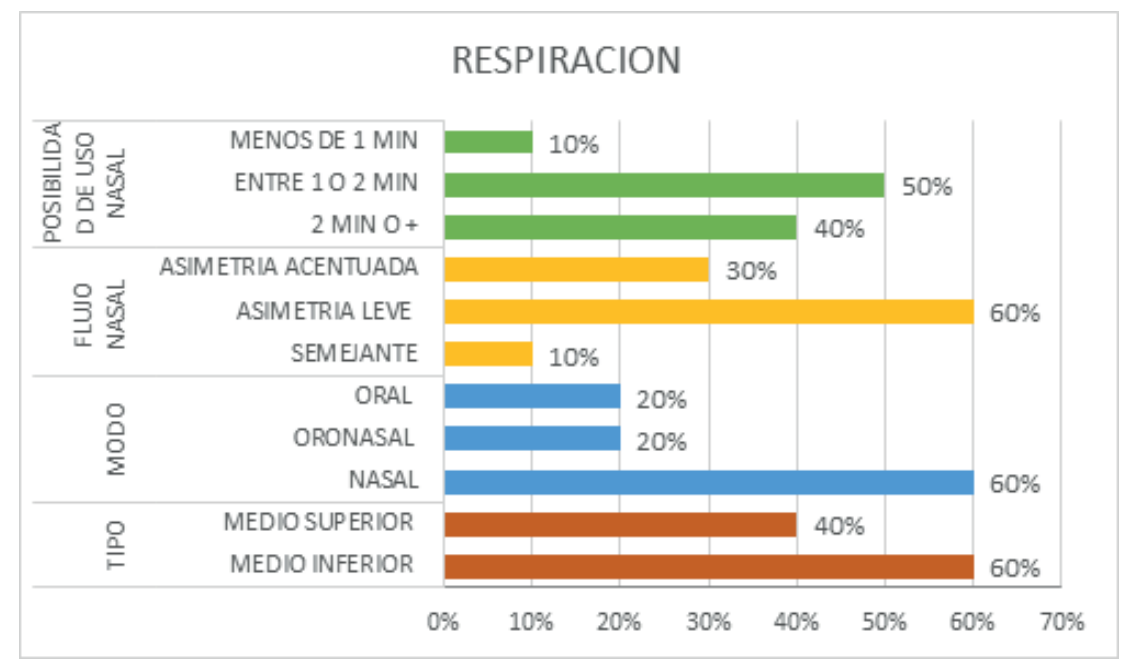

Grafico 7. Respiración. Fuente: Los autores

En la gráfica 8 de acuerdo a la evaluación de la masticación se afirma que realiza la incisión en forma lateral con un $60 \%$ y de segundo lugar de forma lateral con el porcentaje restante, la trituración con los dientes posteriores con un $70 \%$ y con un $10 \%$ de manera ineficiente, eficiente y lengua, el patrón masticatorio es preferencial de manera unilateral obteniendo como punto en común de $60 \%$ de la población y $30 \%$ bilateral alternadamente, el cierre labial cuenta con $80 \%$ asistemático, la velocidad se encuentra disminuida, la mayoría de personas no presentan ruido y contracciones musculares. 


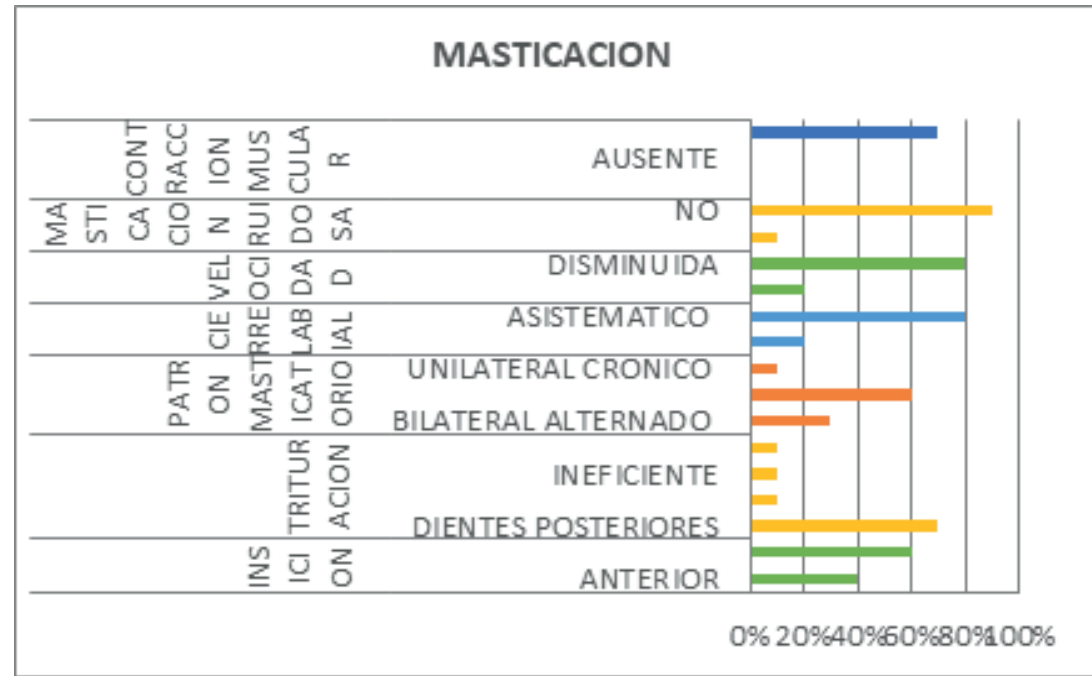

Grafico 8. Masticación. Fuente: Los autores

Grafico 9 muestra las características de la deglución habitual evidenciando con altos porcentajes; residuos después de deglutir, movimientos de cabeza, contracción del mentoniano acentuada, contracción leve del orbicular de los labios, la retención del alimento es parcial, un mal posicionamiento lingual y los labios parcialmente cerrados, determinando una deglución adaptada.

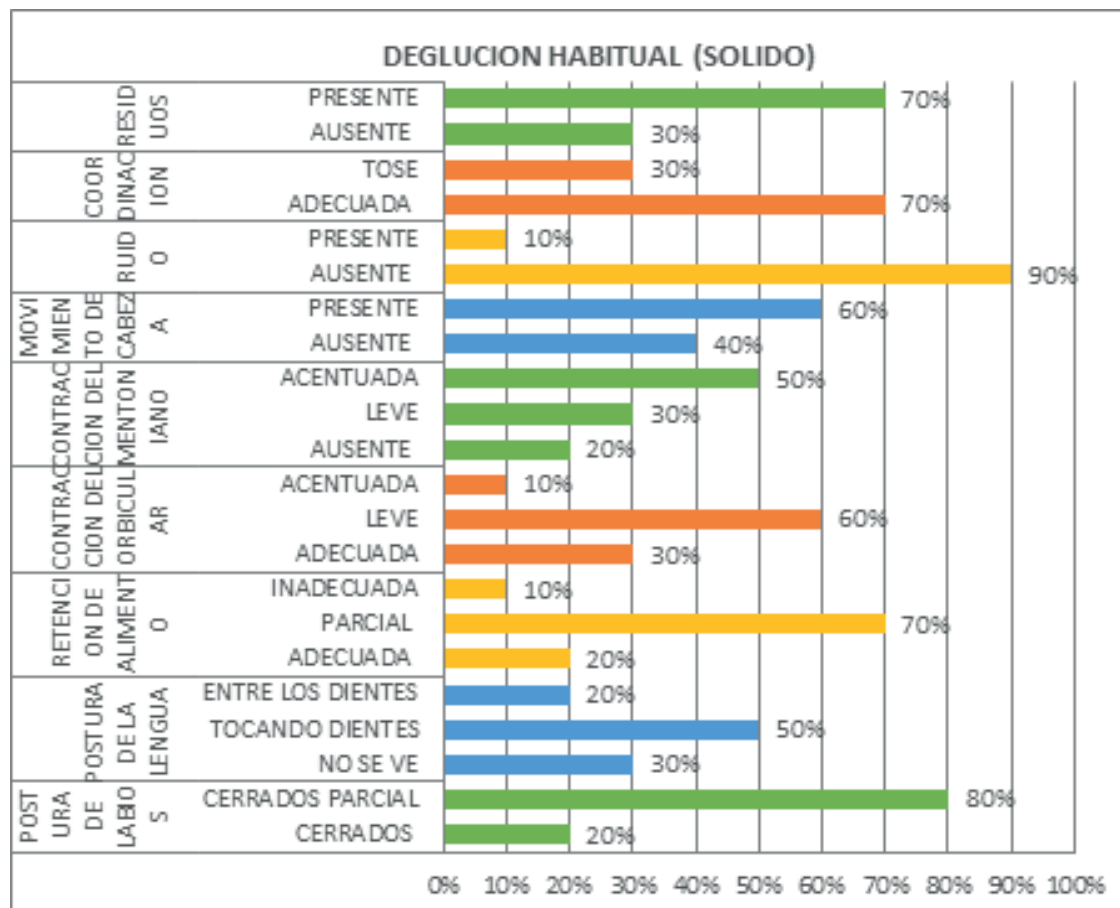

Grafico 9. Deglución habitual con tipo de consistencia solido. Fuente: Los autores

En la grafico 10 Se evidencia en la población muestra; la postura de la lengua no se aprecia, la retención de líquido es inadecuada, y el volumen de líquido es disminuido, una leve contracción del mentoniano, los movimientos de cabeza presentan un $50 \%$ presente - ausente, el ritmo con mejor evidencia a es sorbo a sorbo y el ritmo es sorbo a sorbo a pesar de todo esto se evidencian en la mayoría coordinación en el momento de deglutir sin presentar atoramiento o tos 


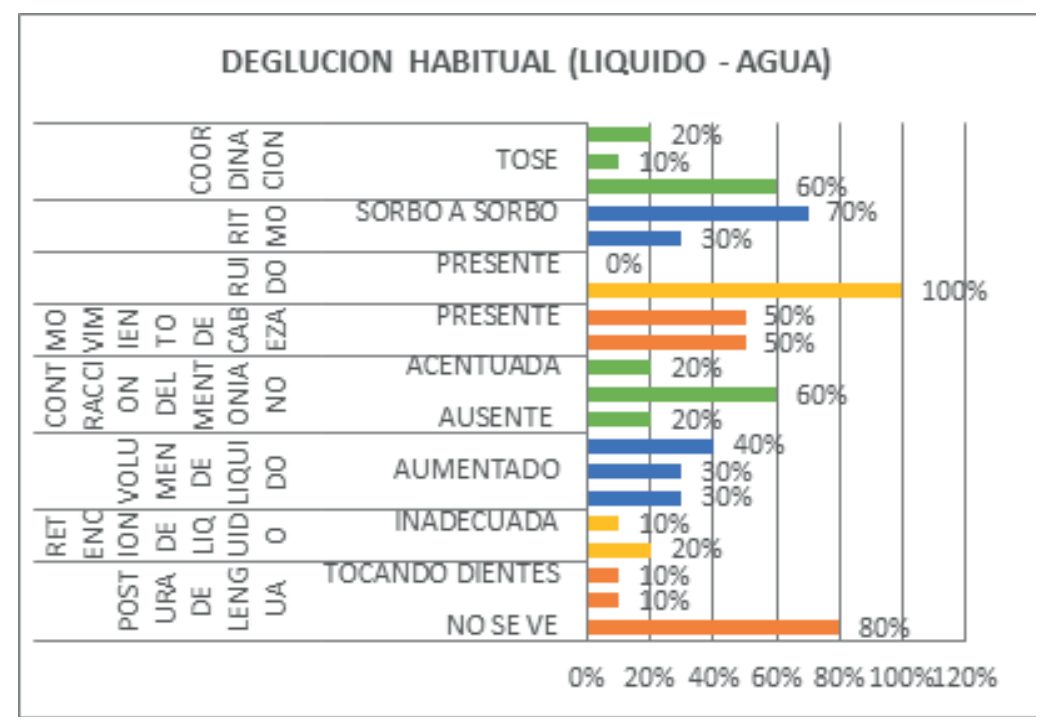

Grafico 11. Deglución habitual con tipo de consistencia liquida. Fuente: Los autores

Grafico 11 , En la deglución dirigida con líquido, se evidencia que la postura de la lengua no se aprecia, la retención de líquido es inadecuada, y el volumen de líquido es disminuido, una leve contracción del mentoniano, los movimientos de cabeza presentan un $50 \%$ presente - ausente, el ritmo con mejor evidencia a es sorbo a sorbo y el ritmo es sorbo a sorbo a pesar de todo esto se evidencian en la mayoría coordinación en el momento de deglutir sin presentar atoramiento o tos

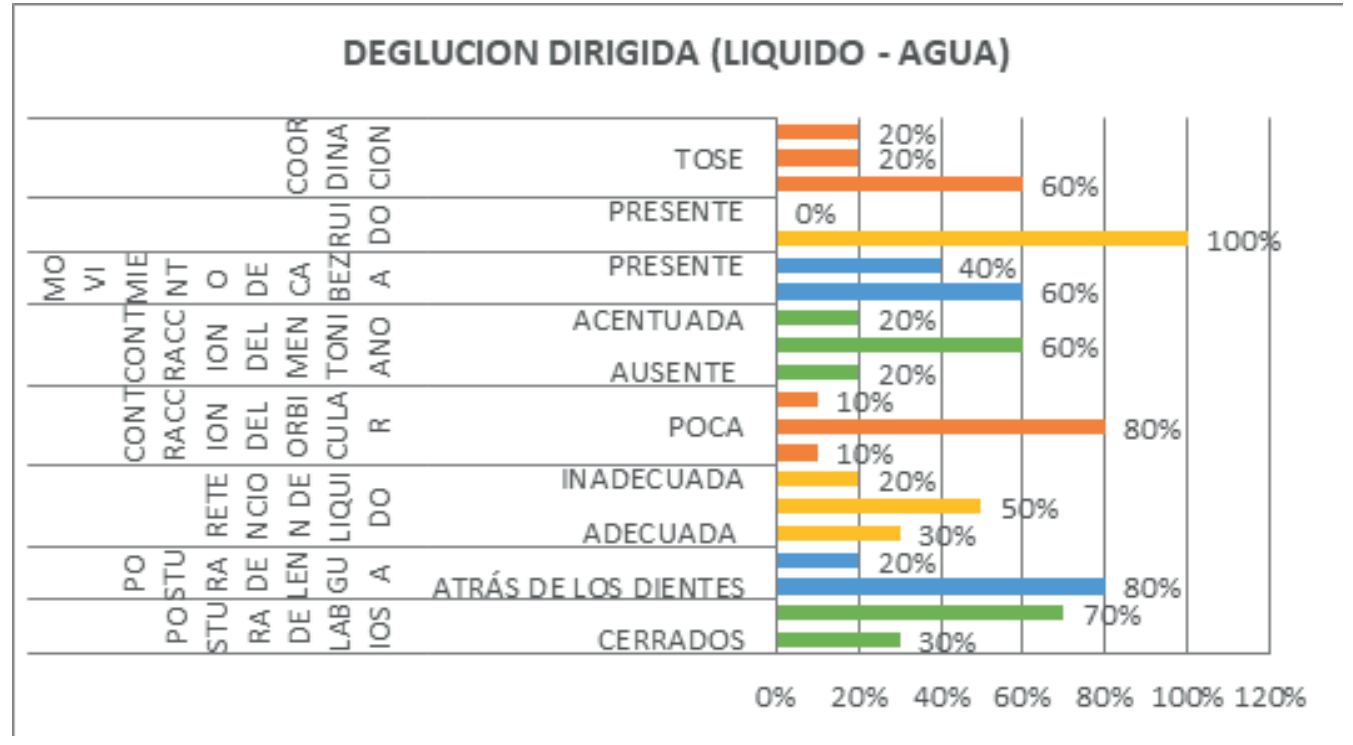

Grafico 10. Deglución habitual con tipo de consistencia liquido. Fuente: Los autores

En esta grafica 12 se observan los resultados obtenidos en los quintos faciales, de acuerdo a esto uno de los primeros datos a destacar es el mayor porcentaje presente en el QUINTO 3 donde $40 \%$ de la muestra (n:4) se evidencia que la distancia del canto externo del ojo derecho a interno derecho está aumentado. 


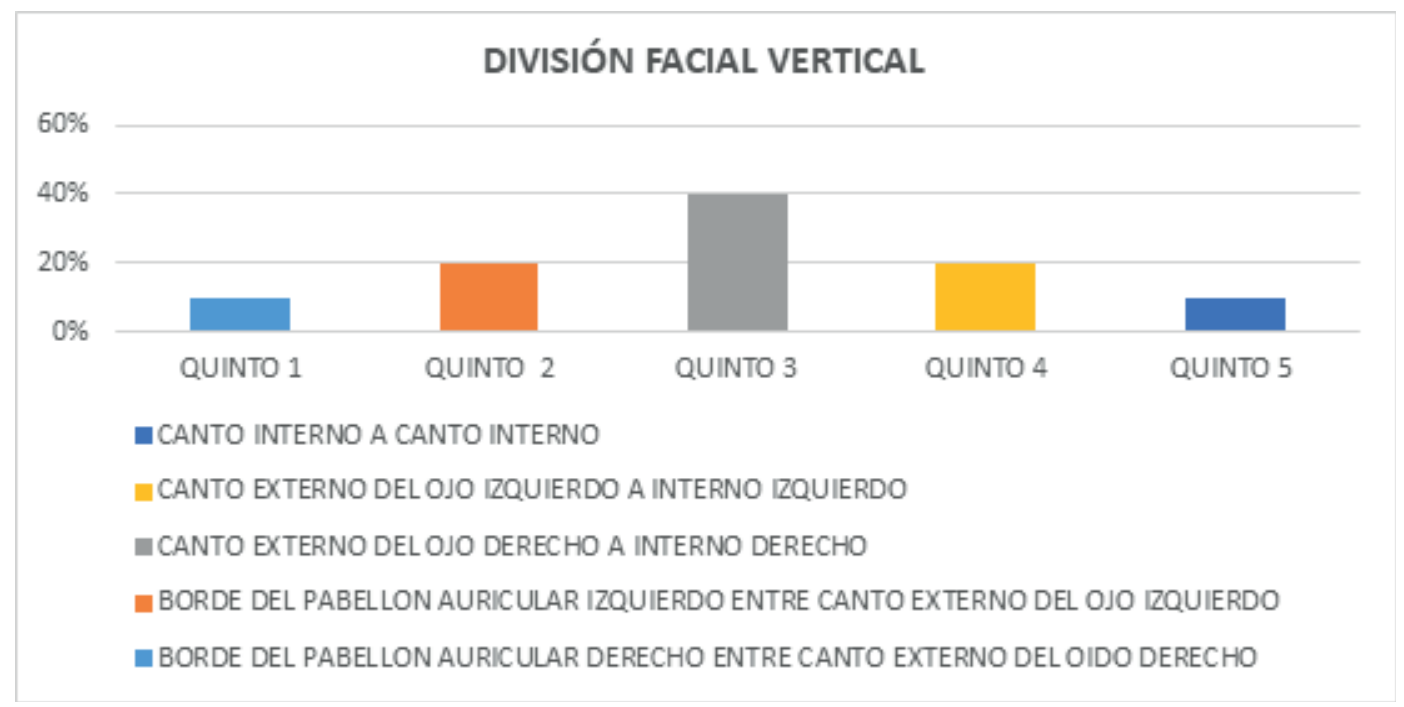

Grafica 12 División facial vertical. Fuente. Los autores

En esta grafica 13 se evidencia mayor alteración en la medida de referencia del subnasal al gnatio correspondiente al tercio inferior mostrando valor de incidencia de un $50 \%$ de la población (n: 5 ) estudio, es decir asimetría facial.

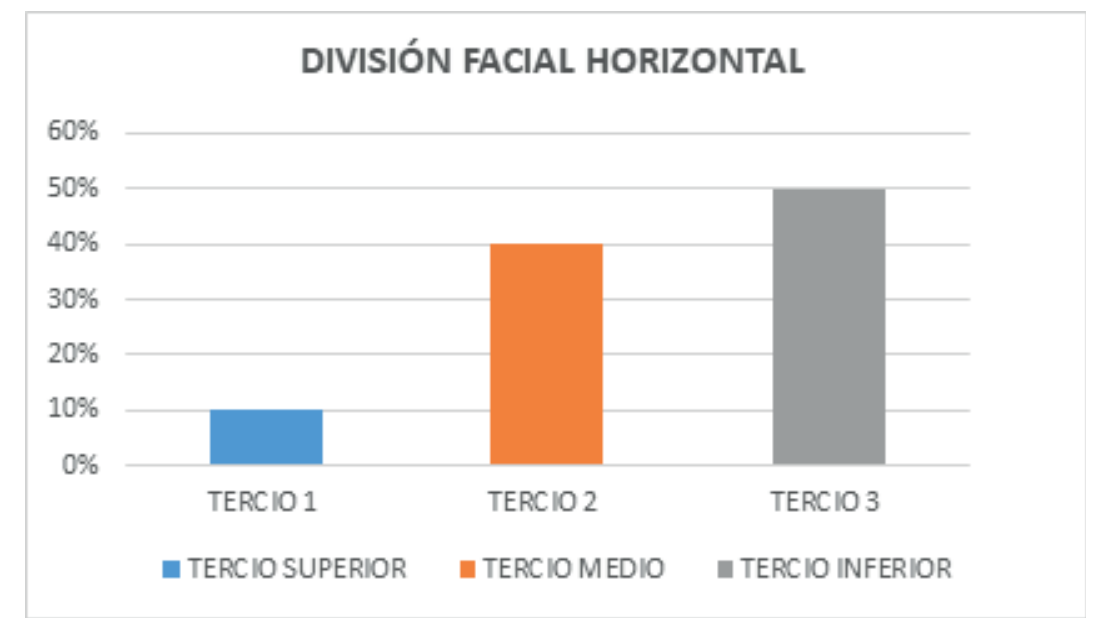

GRAFICA 13 División facial horizontal . Fuente. Los autores

En esta gráfica 14 se evidencia el promedio de los ángulos faciales con opciones de: aumentado, normal y disminuido. Se observa que el ángulo mentocervical presenta el $70 \%$ de la muestra (n:7) en parámetros de normalidad; el $60 \%$ de la muestra estudiada (n:6) tiene el ángulo nasofacial aumentado y $60 \%$ (n: 6) tiene el ángulo nasolabial disminuido. 


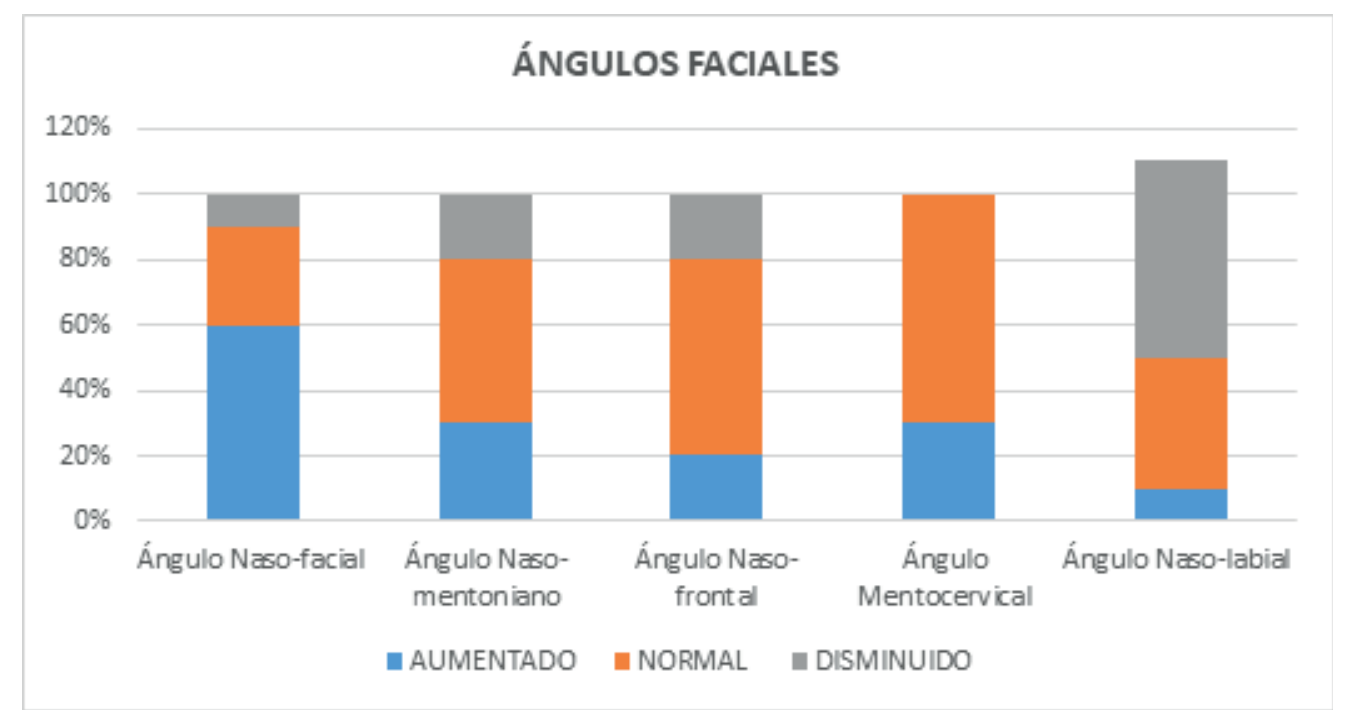

GRAFICO 14 Ángulos faciales . Fuente. Los autores

En este grafica 15 se evidencia los porcentajes de la línea $\mathrm{H}$ Holidaway, en donde se observa que el $50 \%$ de la muestra(n: 5) está alejada de la línea y el $20 \%$ (n:2) traspasa la línea es decir que los labios no están ubicados adecuadamente, el labio inferior está aumentado, sin embargo el $30 \%$ de la muestra (n:3) estudiada presentan la ubicación adecuada de los labios.

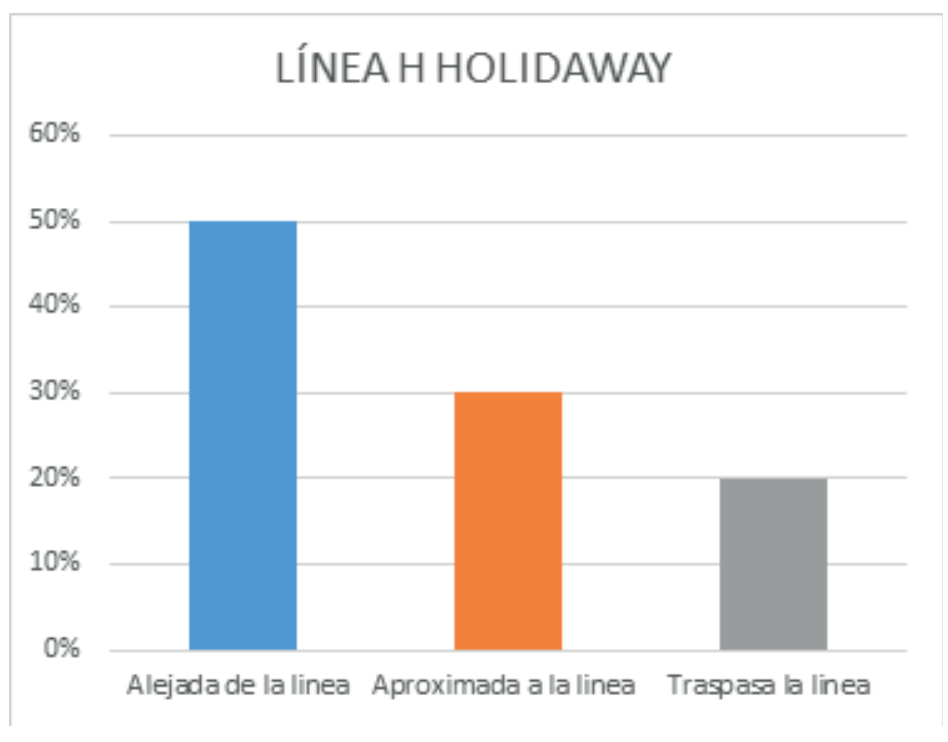

GRAFICA 15 Linea H Holidaway. Fuente. Los autores

En esta gráfica 16 se muestran los porcentajes del Ángulo Z Merrifield en donde se observa que 50\% de la muestra ( $n: 5)$ tiene este ángulo aumentado, conforme a los resultados se puede observar que el $40 \%$ de la muestra está en parámetros de normalidad. 


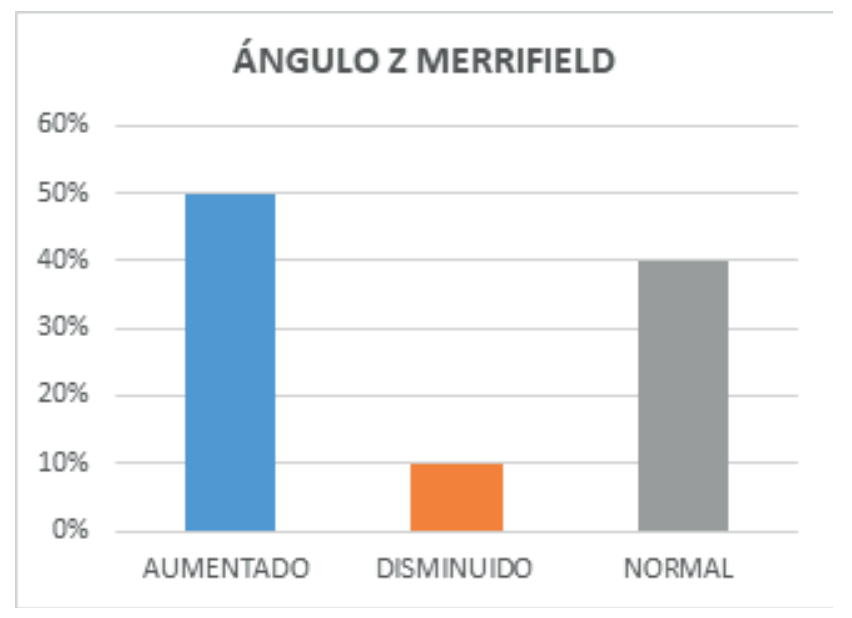

GRAFICO 16 Ángulo Z Merrifield. Fuente. Los autores

En esta grafica 17 se muestran los porcentajes del biotipo facial, en cuanto a los resultados se observa que el $70 \%$ de la muestra (n:7) presenta biotipo dólicofacial es decir dirección de crecimiento vertical (cara larga y estrecha), el 20\% de la muestra (n:2) tiene biotipo braquifacial dirección de crecimiento horizontal (cara corta y ancha), y el $10 \%$ de la muestra (n:1) tienen biotipo mesofacial crecimiento en equilibrio los cuales se encuentran en parámetros de normalidad

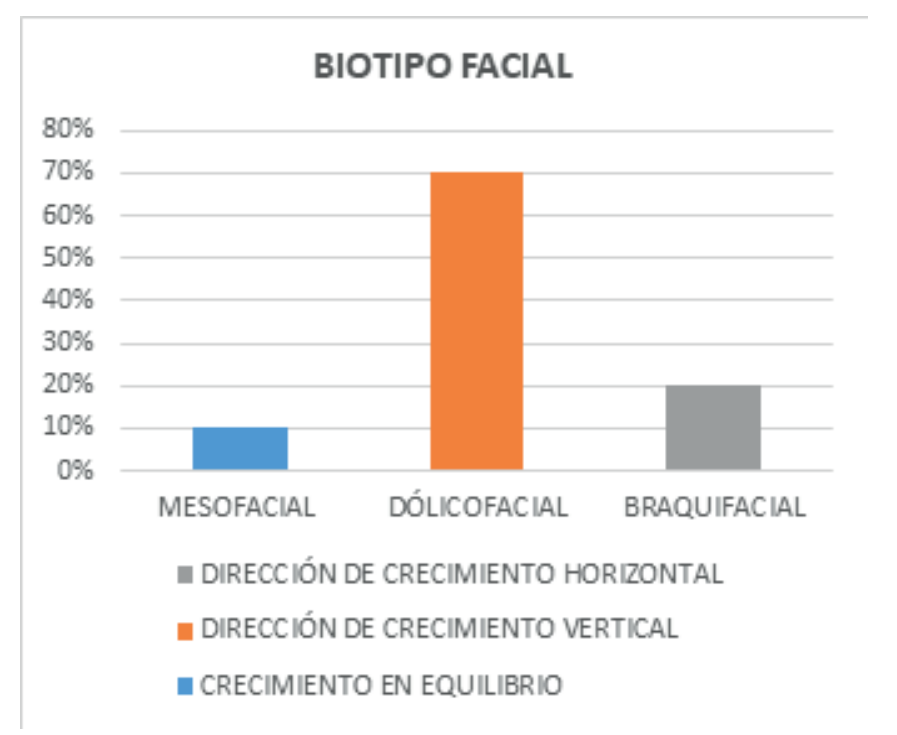

GRAFICO 17 Biotipo facial . Fuente. Los autores

Resultados obtenidos a través del análisis Pont-Korkhaus se evidencia en el usuario 1, en la arcada superior (las distancias entre las fosas centrales de los primeros premolares $(4-4$,$) y la distancia de las fosas$ centrales de los primeros molares (6-6)) describe expansión del maxilar un mayor grado para la arcada en la zona posterior; por otro lado, la longitud de la arcada superior presenta una leve protrusión de incisivos generando afectación directa a la mordida. La altura del paladar arroja un porcentaje de 34\% el cual es menor a la medida estandar que equivale a un $42 \%$, lo cual indica un paladar bajo. Respecto a la arcada inferior (distancia entre las cúspides media vestibular de los primeros premolares (4-4) y la distancia entre las cúspides media vestibular del primer molar (6-6)), se evidencia índice de expansión del maxilar con mayor grado para la parte posterior de la arcada y la longitud de arcada inferior describe un índice negativo, lo que permite determinar una retrusión de incisivos.

En el usuario 2, en la arcada superior, la distancia 4-4 presenta comprensión maxilar y la 6-6 no se puedo obtener debido a que estas piezas dentarias están ausente por consiguiente afecta la realización de la fórmula que permitirá hallar la altura del paladar. La longitud de la arcada superior se evidencia una leve protrusión de incisivos afectando de forma directa a la mordida. Respecto a la arcada inferior, la medida (4-4)y (6-6) muestra una respuesta negativa índice que determina compresión del maxilar, de mayor grado parte posterior. La longitud de arcada inferior arroja resultados de índice negativo, lo que

Revista Científica Signos Fónicos, 2019,5(2): 61-96. ISNN 2422-1716. 
Soto J C; Rojas N S; Téllez G Y; Orozco A M; Sampayo A M; Lizarazo S A. Revista Científica Signos Fónicos, 2019,5(2): 61-96.

permite determinar retrusión de incisivos.

En el usuario 3, en la a la arcada superior, la distancia (4-4) presenta comprensión maxilar y la distancia (6-6) no se pudo obtener debido a que el usuario no desarrollo estas piezas dentarias a su vez afectando la realización de la fórmula que permitirá hallar la altura del paladar. Respecto a la arcada inferior (4-4) y (6-6), se evidencia índice de expansión del maxilar y La longitud de arcada superior e inferior evidencia resultados negativos, lo que permite determinar retrusión de incisivos que pueden comprometer el tipo de mordida.

En el usuario 4, en la a la arcada superior, la distancia entre (4-4) presenta expansión mínima del maxilar superior en la parte anterior respecto a la medida (6-6) no se toma por la ausencia del primer molar derecho lo cual altera el análisis completo de la arcada asimismo afecta la realización de la fórmula que permitirá hallar la altura del paladar. La longitud de arcada superior muestra resultados negativos lo que determina retrusión de incisivos lo cual genera alteración en la mordida. Respecto a la medida de arcada inferior (4-4) evidencia índice de comprensión del maxilar a nivel anterior y la longitud de arcada inferior muestran resultados de índice negativos lo que permite determinar retrusión de incisivos .

En el usuario 5, en la la arcada superior, las distancias entre ( 4-4 ) y la (6-6) presenta sobre expansión del maxilar, por otro lado la longitud de la arcada superior presenta una leve protrusión de incisivos generando afectación a la mordida . La altura del paladar arroja un porcentaje de $25 \%$ el cual es menor a la medida estandar que equivale a un $42 \%$ correspondiente a un paladar bajo. Respecto a la arcada inferior, la medida (4-4) presenta comprensión mínima del maxilar y la medida (6-6), se encuentra dentro de los parámetros de normalidad sin embargo la longitud de la arcada superior e inferior muestran resultados negativo, lo que determina retrusión de incisivos lo cual genera alteración en la mordida

En el usuario 6, respecto a la arcada superior en las distancias (4-4) y la (6-6) que existe una comprensión del maxilar de mayor grado para la parte posterior de la arcada. Por otra parte la longitud de arcada superior, expone también respuesta en límites negativos, característica de leve retrusión de incisivos, y por ende afectación directa o indirectamente en la mordida.

La altura del paladar arroja un porcentaje de $44 \%$ el cual es mayor a la medida estandar que equivale a un $42 \%$ lo cual indica un paladar alto, Respecto a la arcada inferior, la distancia (4-4) y (6-6)arrojan respuesta negativa relacionada con compresión del maxilar. La longitud de la arcada inferior con resultados negativos, señala retrusión de incisivos de mayor grado para esta arcada respecto a la superior

En el usuario 7, respecto a la arcada superior, las distancias (4-4) y la 6-6) expansión del maxilar en este caso de mayor grado en la zona posterior de ambas arcada en relación a la altura del paladar, arroja un porcentaje inferior a $42 \%$ de medida estandar, correspondiendo a un paladar bajo. Respecto a la arcada inferior, la distancia entre la cúspide media vestibular de los primeros premolares (4-4) y la distancia entre las cúspides media vestibular del primer molar (6-6) se evidencia expansión del maxilar mayor grado para la parte posterior de la arcada , La longitud de la arcadas superior e inferior, muestra resultados negativos, señala retrusión de incisivos superiores e inferiores

En el usuario 8, respecto a la arcada superior, la distancias (4-4) presenta compresión mínima, y la (6-6) presenta comprensión del maxilar. La altura del paladar arroja un porcentaje de $38 \%$ el cual es menor a la medida estandar que equivale a un $42 \%$ correspondiendo a un paladar bajo Respecto a la arcada inferior, la distancia entre (4-4) y la distancia (6-6)se evidencia compresión del maxilar, la longitud de las arcadas superior e inferior indica resultados negativos, lo que permite determinar retrusión de incisivos que pueden comprometer el tipo de mordida

En el usuario 9 respecto a la arcada superior, la distancias (4-4) y (6-6) muestra medidas negativas estableciendo una compresión del maxilar de mayor grado para la parte posterior. Por otro lado La longitud de arcada superior, se encuentra en parámetros de crecimiento menor, respecto a los promedios establecidos. La altura del paladar arroja un porcentaje de $27 \%$ el cual es menor a la medida estandar que equivale a un $42 \%$. Respecto a la arcada inferior, la distancia (4-4) no se pudo tomar debido a la ausencia de un premolar y la distancia (6-6) reporta un resultado negativo, lo que permite inducir compresión del maxilar de mayor grado para la parte posterior. La longitud de arcada inferior arroja resultados de índice negativo, que permite determinar retrusión de incisivos que puede comprometer el tipo de mordida.

En el usuario 10 respecto a la arcada superior, las distancias (4-4,) y (6-6) presenta medidas negativas estableciendo una comprensión maxilar con escaso desarrollo transversal de ambas arcadas. La altura 
Soto J C; Rojas N S; Téllez G Y; Orozco A M; Sampayo A M; Lizarazo S A. Revista Científica Signos Fónicos, 2019,5(2): 61-96.

del paladar arroja un porcentaje de $43 \%$ el cual es mayor a la medida estandar que equivale a un $42 \%$ correspondientes a un paladar alto. Longitud de arcada superior se encuentra en parámetros normales respecto a los promedios establecidos por Pont y Korhaus sin embargo la longitud de arcada inferior muestra resultados negativo evidenciando retrusión de incisivos que compromete la mordida

\begin{tabular}{|c|c|c|c|c|c|c|c|c|c|}
\hline & & indice de Kc & orkhaus - U & Jsuarios cor & n diagnóstic & cos neurol & lógicos & & \\
\hline Usua- & $\Sigma$ Incisivos & Fosas ce & $\begin{array}{l}\text { entrales } \\
-4\end{array}$ & Fosas Cent & trales 6-6 & Long & gitud & $\begin{array}{l}\text { Pro- } \\
\text { fundi- } \\
\text { dad del }\end{array}$ & $\begin{array}{l}\text { Altura } \\
\text { del pa- }\end{array}$ \\
\hline & & Superior & Inferior & Superior & Inferior & LAS & LAI & $\begin{array}{l}\text { pala- } \\
\text { dar }\end{array}$ & \\
\hline $\begin{array}{c}\text { Usuario } \\
1\end{array}$ & $27 \mathrm{~mm}$ & $\begin{array}{c}38-32 \\
\mathrm{~mm} \\
(6 \mathrm{~mm})\end{array}$ & $\begin{array}{c}33-32 \\
\mathrm{~mm} \\
(1 \mathrm{~mm})\end{array}$ & $\begin{array}{c}45-41,5 \\
\mathrm{~mm} \\
(-3,5 \mathrm{~mm})\end{array}$ & $\begin{array}{c}51-41,5 \\
\mathrm{~mm} \\
(9,5 \mathrm{~mm})\end{array}$ & $\begin{array}{c}19-16 \\
\mathrm{~mm} \\
(3 \mathrm{~mm})\end{array}$ & $\begin{array}{c}12-16 \\
\mathrm{~mm} \\
(-4 \mathrm{~mm})\end{array}$ & $18 \mathrm{~mm}$ & $34 \%$ \\
\hline $\begin{array}{c}\text { Usuario } \\
2\end{array}$ & $27 \mathrm{~mm}$ & $\begin{array}{c}40-32 \\
\mathrm{~mm} \\
(8 \mathrm{~mm})\end{array}$ & $\begin{array}{c}31-32 \\
\mathrm{~mm} \\
(-1 \mathrm{~mm})\end{array}$ & No aplica & $\begin{array}{c}51-41,5 \\
\mathrm{~mm} \\
(9,5 \mathrm{~mm})\end{array}$ & $\begin{array}{c}12-16 \\
\mathrm{~mm} \\
(-4 \mathrm{~mm})\end{array}$ & $\begin{array}{c}12-16 \\
\mathrm{~mm} \\
(-4 \mathrm{~mm})\end{array}$ & $21 \mathrm{~mm}$ & $\begin{array}{c}\text { No apli- } \\
\text { ca }\end{array}$ \\
\hline $\begin{array}{c}\text { Usuario } \\
3\end{array}$ & $34 \mathrm{~mm}$ & $\begin{array}{c}34-40 \\
\mathrm{~mm} \\
(-6 \mathrm{~mm})\end{array}$ & $\begin{array}{c}30-40 \\
\mathrm{~mm} \\
(10 \mathrm{~mm})\end{array}$ & No aplica & No aplica & $\begin{array}{c}12-19.5 \\
\mathrm{~mm} \\
(7,5 \mathrm{~mm})\end{array}$ & $\begin{array}{c}13-19.5 \\
\mathrm{~mm} \\
(-6,5 \mathrm{~mm})\end{array}$ & $18 \mathrm{~mm}$ & $\begin{array}{c}\text { No apli- } \\
\text { ca }\end{array}$ \\
\hline $\begin{array}{c}\text { Usuario } \\
4\end{array}$ & $37 \mathrm{~mm}$ & $\begin{array}{c}44-43,5 \\
\mathrm{~mm} \\
(0,5 \mathrm{~mm})\end{array}$ & $\begin{array}{c}35-43,5 \\
\mathrm{~mm} \\
(-8,5 \mathrm{~mm})\end{array}$ & No aplica & $\begin{array}{c}57-57 \mathrm{~mm} \\
(0 \mathrm{~mm})\end{array}$ & $\begin{array}{c}19-22 \\
\mathrm{~mm} \\
(-3 \mathrm{~mm})\end{array}$ & $\begin{array}{c}19-22 \\
\mathrm{~mm} \\
(-3 \mathrm{~mm})\end{array}$ & $18 \mathrm{~mm}$ & $\begin{array}{c}\text { No apli- } \\
\text { ca }\end{array}$ \\
\hline $\begin{array}{c}\text { Usuario } \\
5\end{array}$ & $28 \mathrm{~mm}$ & $\begin{array}{c}39-33 \\
\mathrm{~mm} \\
(6 \mathrm{~mm})\end{array}$ & $\begin{array}{c}\text { 30-33 } \\
\mathrm{mm} \\
(3 \mathrm{~mm})\end{array}$ & $\begin{array}{c}48-43 \mathrm{~mm} \\
(5 \mathrm{~mm})\end{array}$ & $\begin{array}{c}43-43 \mathrm{~mm} \\
(0 \mathrm{~mm})\end{array}$ & $\begin{array}{c}16-16 \\
\mathrm{~mm} \\
(0,5 \mathrm{~mm})\end{array}$ & $\begin{array}{c}14-16.5 \\
\mathrm{~mm} \\
(2.5 \mathrm{~mm})\end{array}$ & $17 \mathrm{~mm}$ & $25 \%$ \\
\hline $\begin{array}{c}\text { Usuario } \\
6\end{array}$ & $34 \mathrm{~mm}$ & $\begin{array}{c}38-40 \\
\mathrm{~mm} \\
(-2 \mathrm{~mm})\end{array}$ & $\begin{array}{c}33-40 \\
\mathrm{~mm} \\
(-7 \mathrm{~mm})\end{array}$ & $\begin{array}{c}47-52,2 \\
\mathrm{~mm} \\
(-5,5 \mathrm{~mm})\end{array}$ & $\begin{array}{c}46-52,5 \\
\mathrm{~mm} \\
(-6,5 \mathrm{~mm})\end{array}$ & $\begin{array}{c}19-19,5 \\
\mathrm{~mm} \\
(-0,5 \mathrm{~mm})\end{array}$ & $\begin{array}{c}15-19,5 \\
\mathrm{~mm} \\
(-4,5 \mathrm{~mm})\end{array}$ & $19 \mathrm{~mm}$ & $44 \%$ \\
\hline $\begin{array}{c}\text { Usuario } \\
7\end{array}$ & $29 \mathrm{~mm}$ & $\begin{array}{c}\text { 37-34 } \\
\mathrm{mm} \\
(3 \mathrm{~mm})\end{array}$ & $\begin{array}{c}39-34 \\
\mathrm{~mm} \\
(5 \mathrm{~mm})\end{array}$ & $\begin{array}{c}54-44,5 \\
\mathrm{~mm} \\
(9,5 \mathrm{~mm})\end{array}$ & $\begin{array}{c}48-44,5 \\
\mathrm{~mm} \\
(3,5 \mathrm{~mm})\end{array}$ & $\begin{array}{c}15-17 \\
\mathrm{~mm} \\
(-2 \mathrm{~mm})\end{array}$ & $\begin{array}{c}14-17 \\
\mathrm{~mm} \\
(-3 \mathrm{~mm})\end{array}$ & $15 \mathrm{~mm}$ & $27 \%$ \\
\hline $\begin{array}{c}\text { Usuario } \\
8\end{array}$ & $36 \mathrm{~mm}$ & $\begin{array}{c}39-42,5 \\
\mathrm{~mm} \\
(3,05 \mathrm{~mm})\end{array}$ & $\begin{array}{c}49-42,5 \\
\mathrm{~mm} \\
(7,05 \mathrm{~mm})\end{array}$ & $\begin{array}{c}49-55 \mathrm{~mm} \\
(6 \mathrm{~mm})\end{array}$ & $\begin{array}{c}43-55 \mathrm{~mm} \\
(12 \mathrm{~mm})\end{array}$ & $\begin{array}{c}16-21 \\
\mathrm{~mm} \\
(5 \mathrm{~mm})\end{array}$ & $\begin{array}{c}15-21 \\
\mathrm{~mm} \\
(6 \mathrm{~mm})\end{array}$ & $22 \mathrm{~mm}$ & $38 \%$ \\
\hline $\begin{array}{c}\text { Usuario } \\
9\end{array}$ & $38 \mathrm{~mm}$ & $\begin{array}{c}41-44,7 \\
\mathrm{~mm} \\
(-3,7 \mathrm{~mm})\end{array}$ & No aplica & $\begin{array}{c}49-58,5 \\
\mathrm{~mm} \\
(-7,5 \mathrm{~mm})\end{array}$ & $\begin{array}{c}\begin{array}{c}51-44,5 \\
\mathrm{~mm}\end{array} \\
(3,5 \mathrm{~mm})\end{array}$ & $\begin{array}{c}22-23 \\
\mathrm{~mm} \\
(-1 \mathrm{~mm})\end{array}$ & $\begin{array}{c}15-23 \\
\mathrm{~mm} \\
(-8 \mathrm{~mm})\end{array}$ & $17 \mathrm{~mm}$ & $27 \%$ \\
\hline $\begin{array}{c}\text { Usuario } \\
10\end{array}$ & $35 \mathrm{~mm}$ & $\begin{array}{c}39-41,2 \\
\mathrm{~mm} \\
(-2,2 \mathrm{~mm})\end{array}$ & $\begin{array}{c}39-41,2 \\
\mathrm{~mm} \\
(-2,2 \mathrm{~mm})\end{array}$ & $\begin{array}{c}50-54 \mathrm{~mm} \\
(-4 \mathrm{~mm})\end{array}$ & $\begin{array}{c}49-54 \mathrm{~mm} \\
(-5, \mathrm{~mm})\end{array}$ & $\begin{array}{c}20-20 \\
\mathrm{~mm} \\
(0 \mathrm{~mm})\end{array}$ & $\begin{array}{c}16-20 \\
\mathrm{~mm} \\
(-4 \mathrm{~mm})\end{array}$ & $15 \mathrm{~mm}$ & $43 \%$ \\
\hline
\end{tabular}

Tabla 2. Análisis Índice de Korkhaus

Fuente: Los autores.

Este grafico está conformada por 4 categorías de las cuales se puede evidenciar: presencia de crisis convulsivas en los usuarios 1, 2, 3, 4, 5, 7 Y 8. Cirugías de cabeza y cuello en usuarios 3 y 8 . Respiración toraxica en sujetos 1, 2, 3, 4, 5 y 9 y clavicular en 6, 7, 8 y 10. Gastrostomía en usuario 8. 


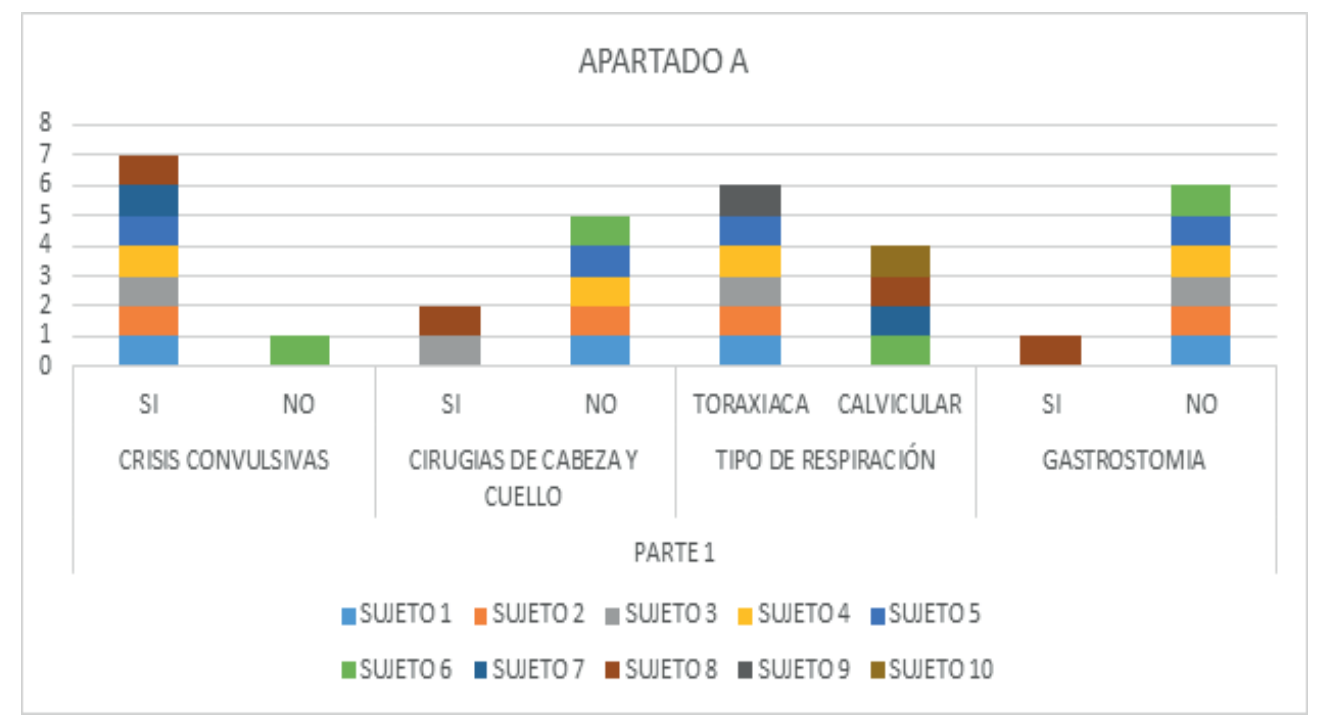

Grafica 18: apartado A. Fuente: los autores

En este grafico podemos evidenciar que fueron utilizados utensilios pastosos, sólidos y líquidos, a excepción del sujeto 8 , además los usuarios $1,2,6,7$, y 8 presentan postura semifowler en reposo, mientas que los sujetos $3,4,5,9$ y 10 su posición es reposo es sentado. Durante la alimentación los sujetos $1,2,7$, y 8 presenta posición semifowler y los sujetos $4,5,6,9$ y 10 su posición es sentado.

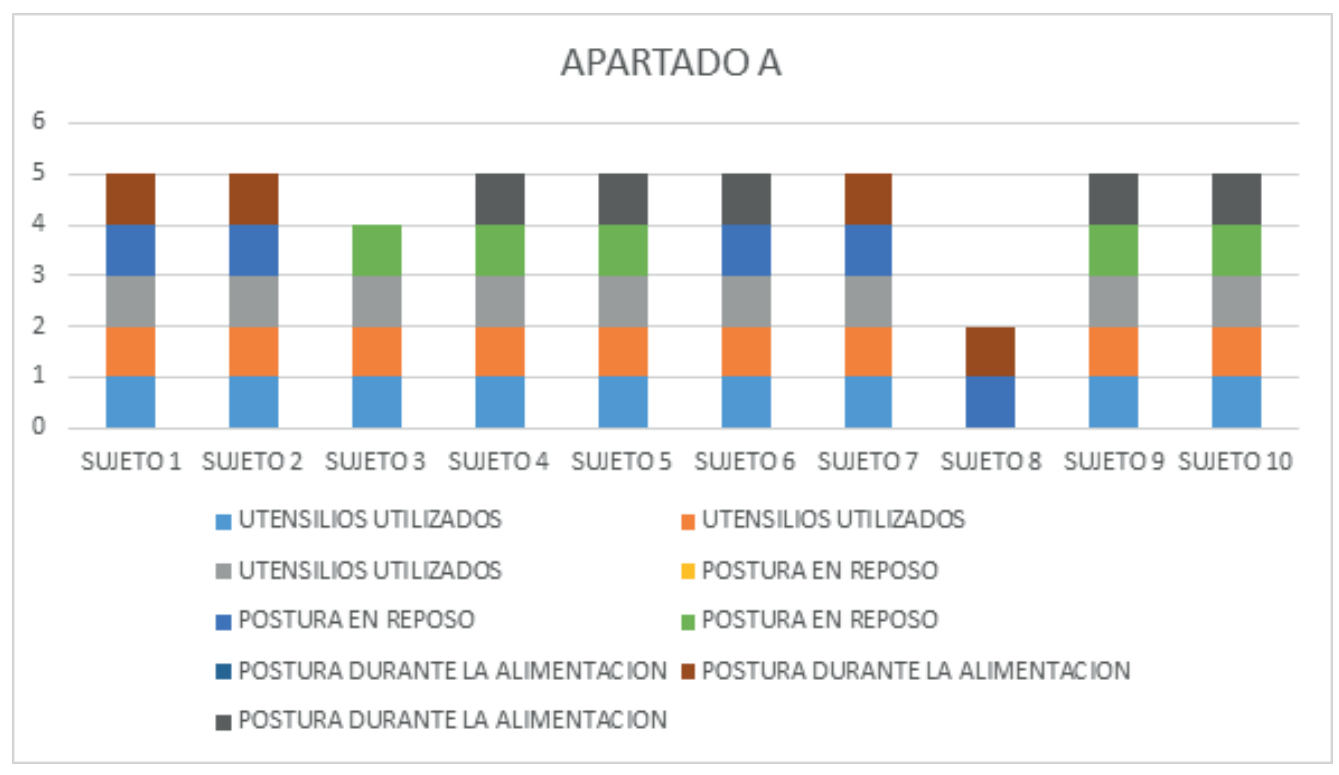

Grafica 19: apartado A. Fuente: los autores

En este grafico podemos observar que en todos los sujetos está presente el reflejo de tos, los sujetos $1,23,6,7$ y 8 presentan el reflejo de masticación, reflejo de vomito se encuentra en la mayoría de los sujetos a excepción del número 5 , el reflejo de mordida está presente en los sujetos 2, 6, 7, 8 y 9. El reflejo de paladar se encuentra presente en los sujetos a excepción del número 9. 


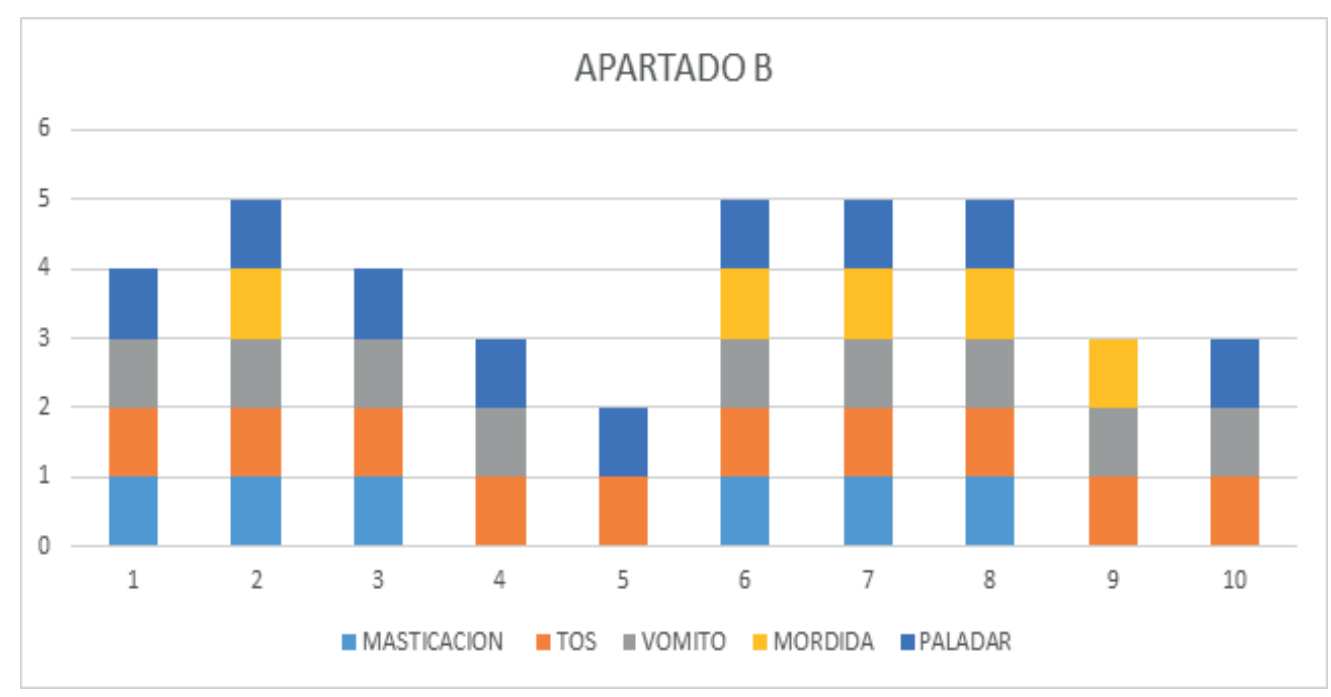

Grafica 20: apartado B. Fuente: los autores

En este grafico podemos evidenciar que los sujetos 1,2,6Y 8 presentan sensibilidad facial normal ante el toque y toque con presión, los sujetos $1,2,3,4,5,6,8$ y 10 presentan sensibilidad intraoral ante el toque y toque con presión, los sujetos $1,2,3,6,7,8$ y 9 presentan sensibilidad ante el toque y toque con presión en la lengua, los sujetos 1, 2, 4, 6, 7 y 8 presentan sensibilidad ante el toque en el paladar, los sujetos 6 y 7 presentan hiposensibilidad, los sujetos 1, 2, 4, 5, 8 y 9 presentan hipersensibilidad ante el toque y los sujetos 3,10 presentan sensibilidad normal ante el toque y toque con presión.

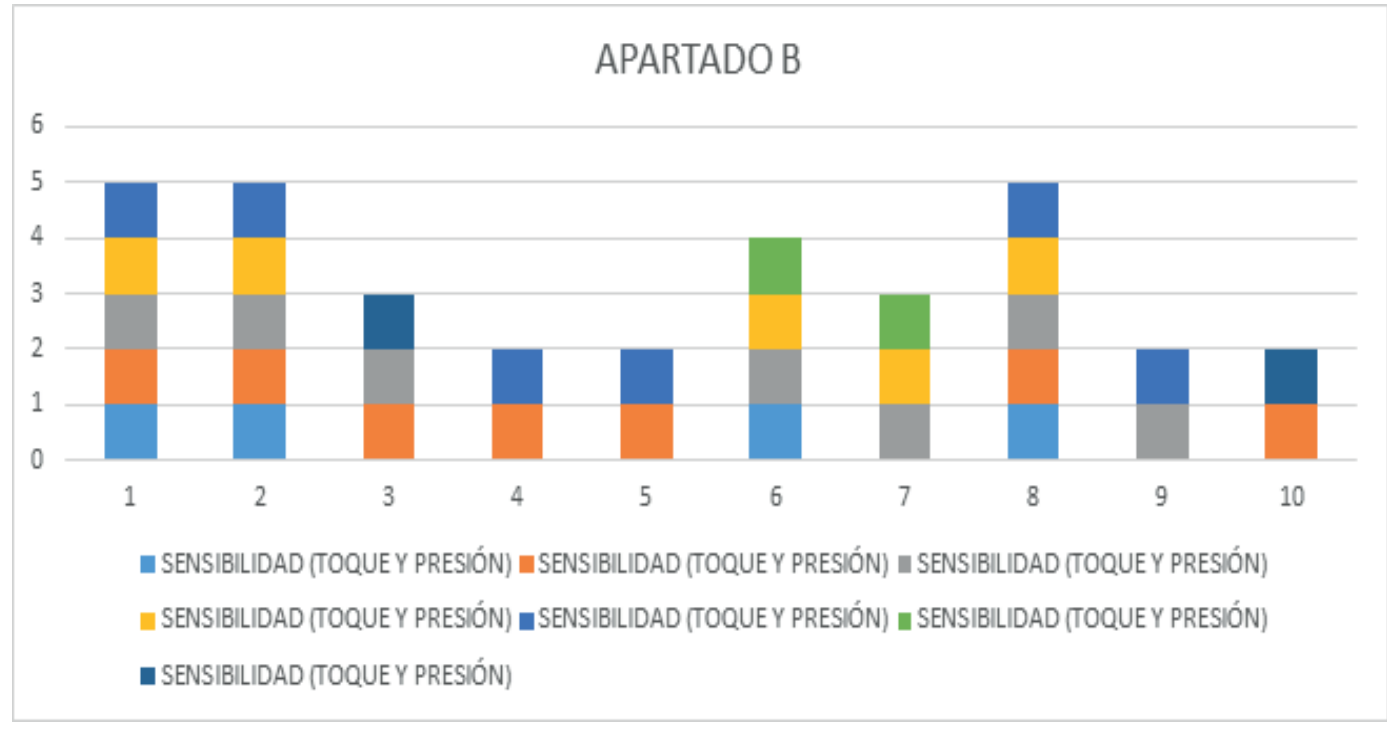

Grafica 21: apartado B. Fuente: los autores

Este grafico está compuesto por 4 categorías en donde se puede observar que los sujetos presentan movilidad de la lengua, movilidad de la mandíbula, movilidad de los labios y los sujetos 1, 2, 6, 9 y 10 presentan movilidad del paladar. 


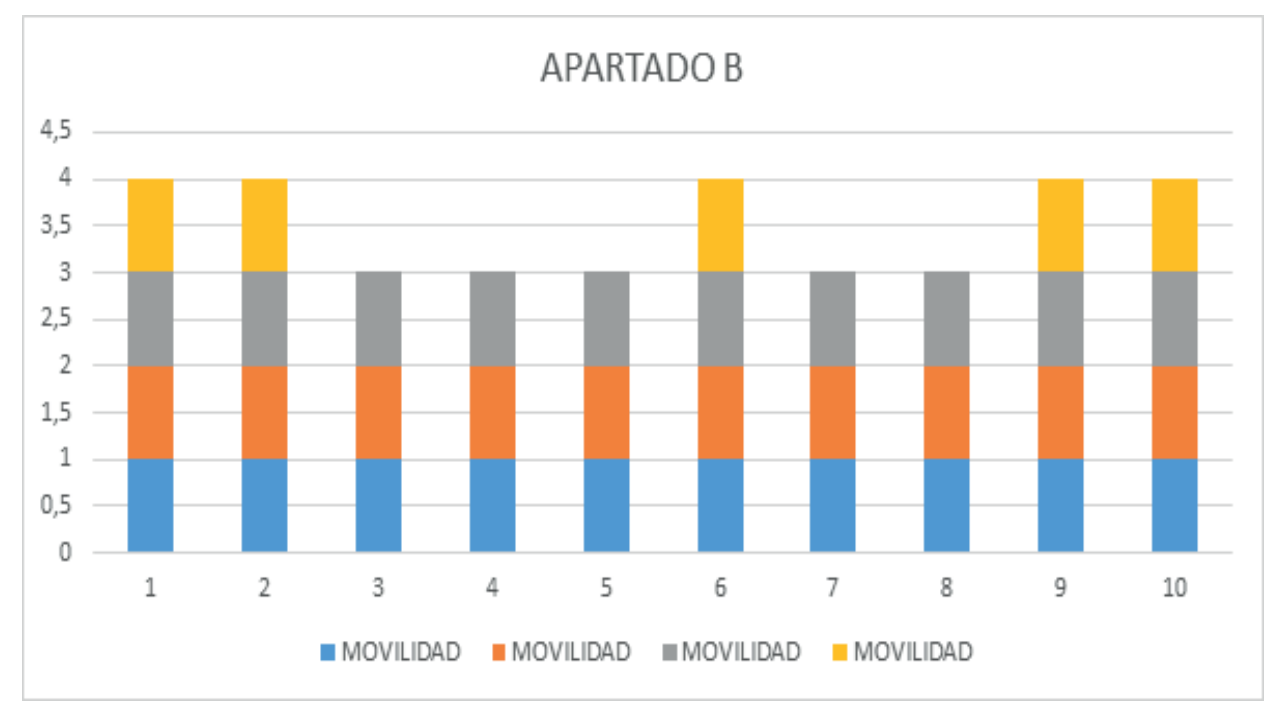

Grafica 22: apartado B. Fuente: los autores

Este grafico podemos observar en cuanto a la consistencia pastosa que los sujetos 1, 3, 6, 9 y 10 no presentan escape oral, por el contrario los sujetos $2,4,5$ y 7 si presentan escape oral, de igual forma los sujetos $1,3,9$ y 10 presentan transito oral adecuado mientras que los sujetos $2,4,5,6,7$ y 8 presentan transito oral lento, los sujetos 4 y 6 presentan en número de degluciones única, los sujetos 1, 2, 3, 4, 6, 7,9 y 10 presentan degluciones múltiples, el sujeto 7 presencia de tos y en el usuario 8 no se evidencian ninguna de las características evaluadas ya que su alimentación no es oral.

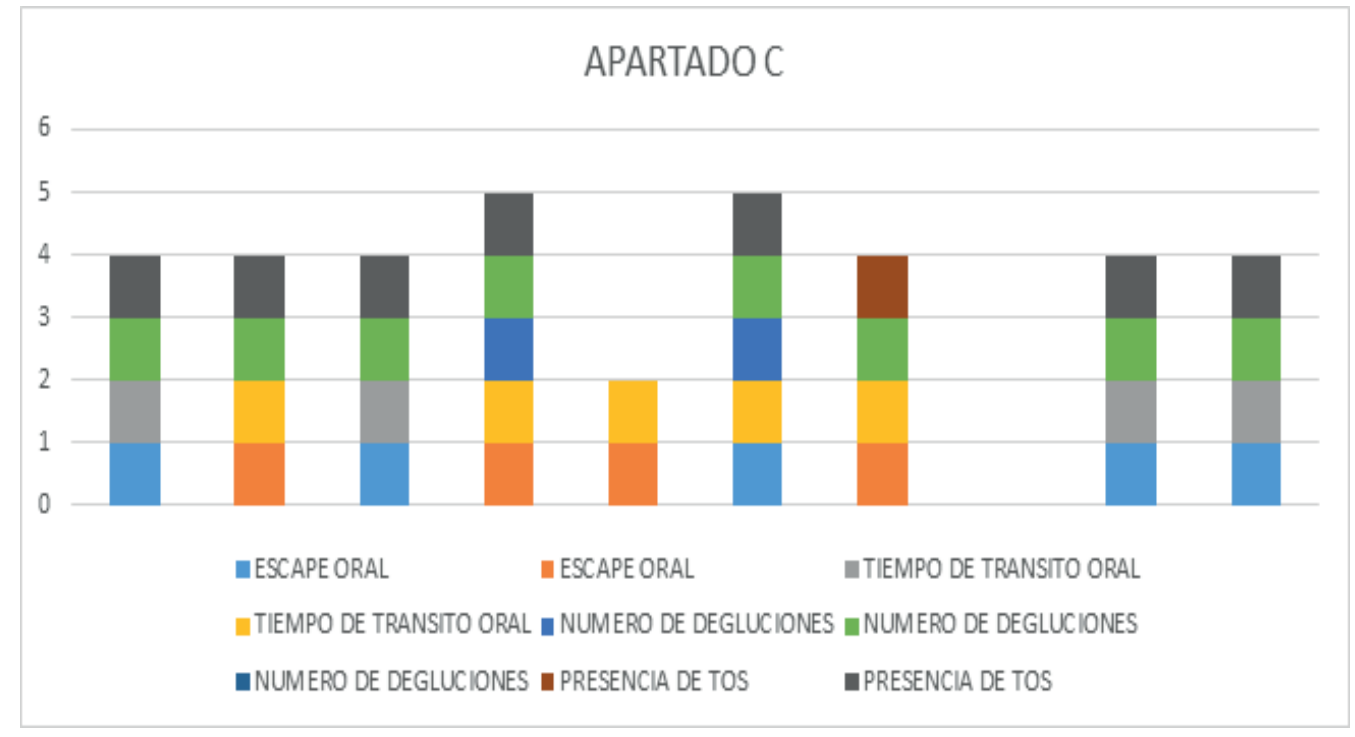

Grafica 23: apartado C. Fuente: los autores

En este grafico podemos observar que los sujetos 1, 2 y 4 presentan tiempo de transito oral adecuado, los sujetos $3,5,6,7,9$ y 10 presentan tiempo de transito oral lento, de igual forma se evidencia que os sujetos 3, 4, 5, 6 y 7 presentan número de degluciones múltiples y por el contrario los sujetos 9 y 10 presentan número de degluciones única, los usuarios 2, 3, 5, 6 y 7 presentan ausencia de tos. En el usuario 8 no se evidencian ninguna de las características evaluadas ya que su alimentación no es oral. 


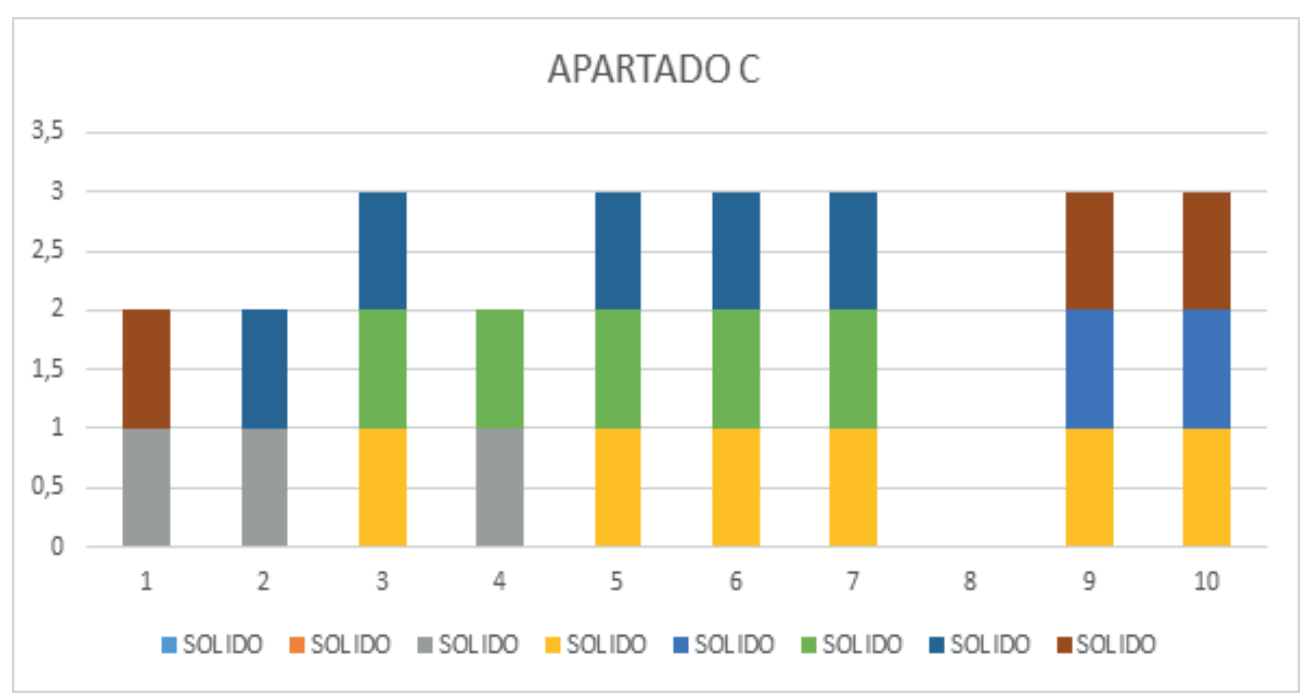

Grafica 24: apartado C. Fuente: los autores

En este grafico podemos observar que los sujetos 1, 3, 4, 7, 9 y 10 presentan escape oral y por el contrario los sujetos 2,5 y 6 no presenta escape oral, los sujetos 2, 3, 4, 5, 6 y 7 presenta transito oral lento y los sujetos 1,9 y 10 presentan transito oral adecuado, los sujetos 2, 3, 4, 5, 6 y 7 presenta número de degluciones múltiples, mientras que los sujetos 9 y 10 presentan número de degluciones única, en los sujetos 2, 3, 5, 6 y 7 presentan ausencia de tos. En el usuario 8 no se evidencian ninguna de las características evaluadas ya que su alimentación no es oral.

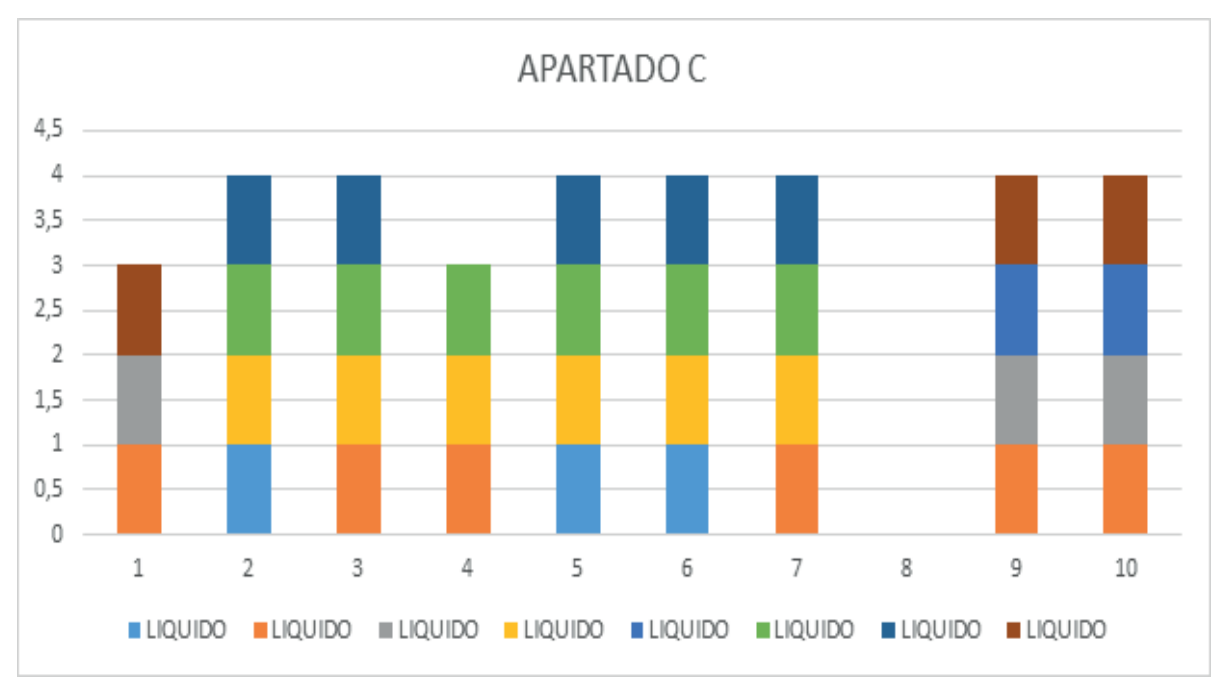

Grafica 25: apartado C. Fuente: los autores

En este grafico podemos observar 7 niveles en los que encontramos en el nivel 1 un sujeto, nivel 42 sujetos y en e 5 nivel 7 sujetos. En los niveles 2, 3, 6 y 7 se no ubica ningún sujeto ya que no presentan las características que dichos niveles describen. 


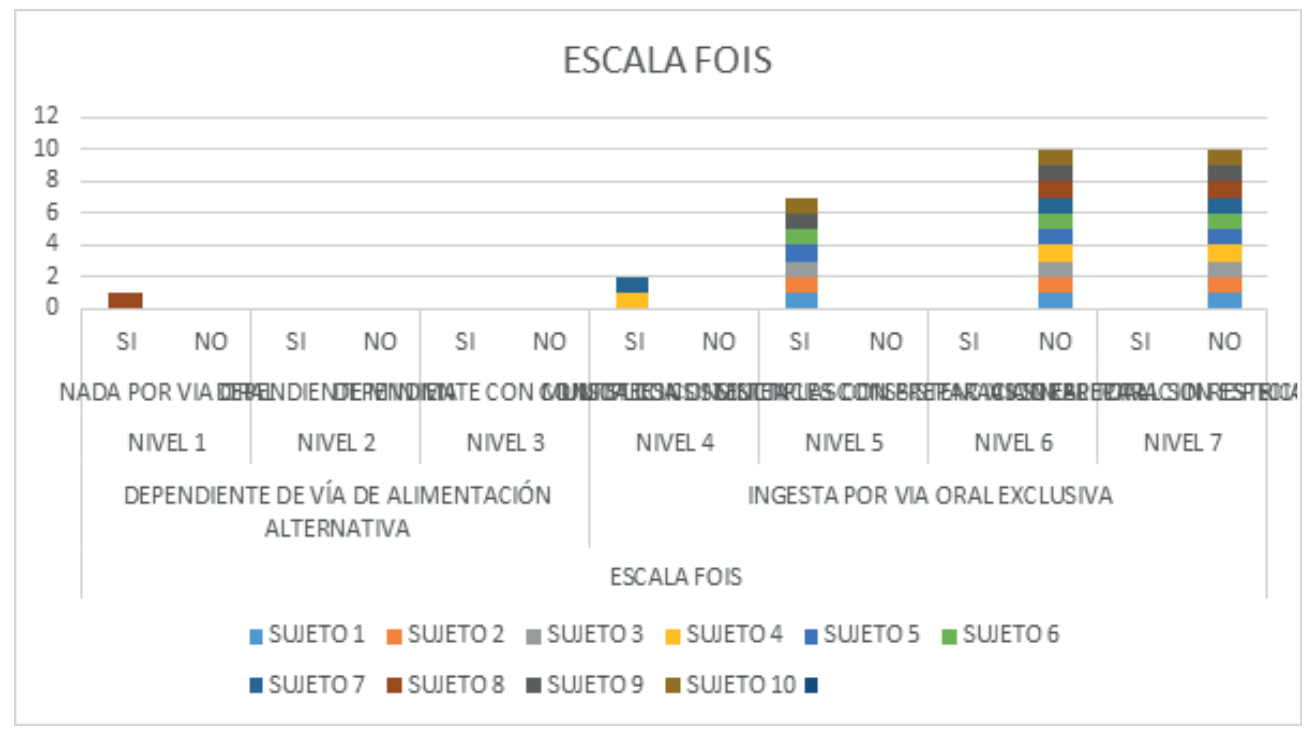

Grafica 26: Escala FOIS. Fuente: los autores

En este grafico podemos evidenciar que durante el proceso de la toma de la saturación antes, durante y después de ingerir los alimentos, en las diferentes consistencias ninguno delos sujetos presento alteración, ubicándose el rango más bajo en $94 \%$ y el más alto en $98 \%$.
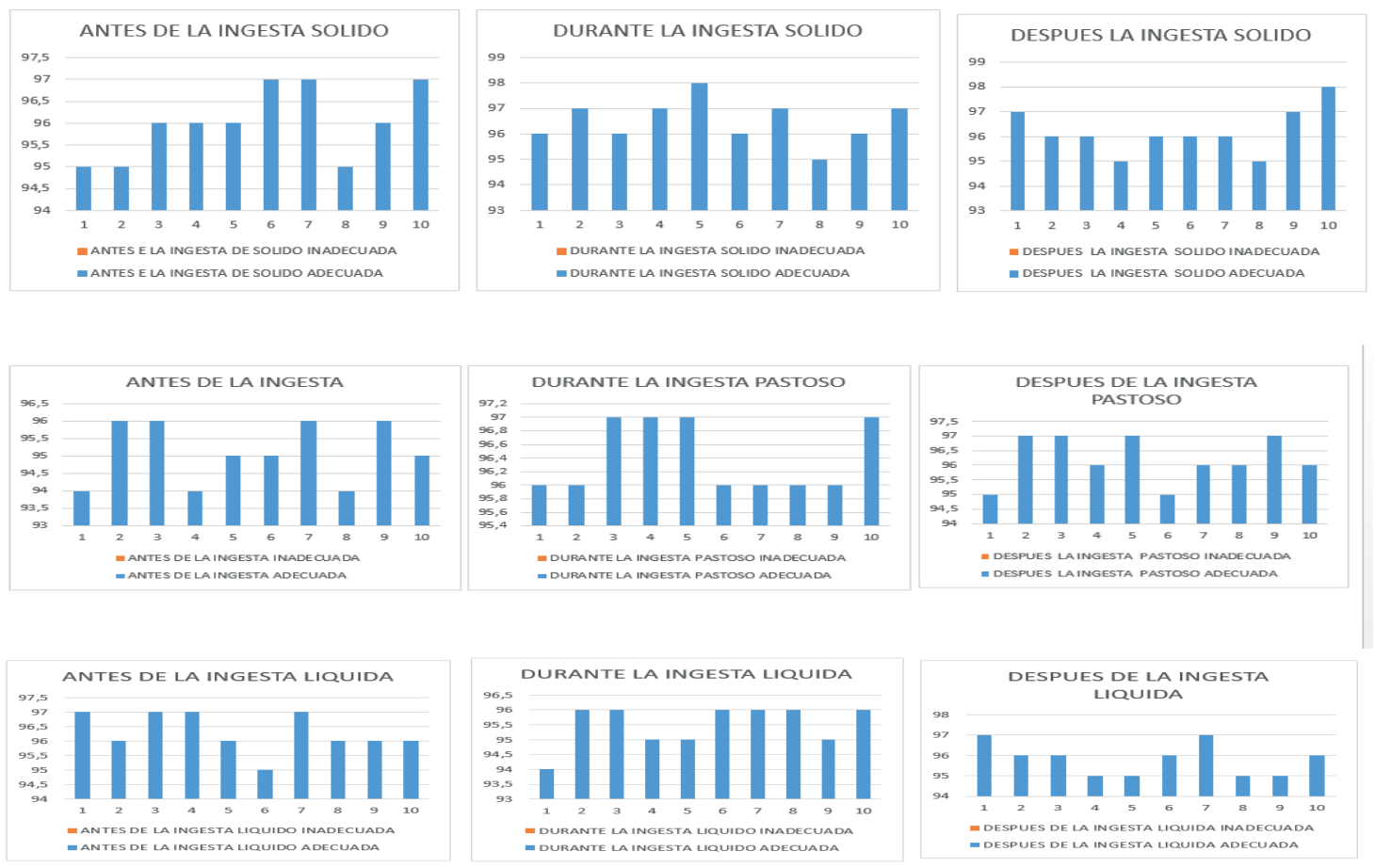

Grafica 27: Oximetria. Fuente: los autores

Se observa que el nervio con mayor frecuencia de alteración en los sujetos del 1 al 5 dentro de la modalidad sensitiva general es el VII NC; en la modalidad sensitiva especial el VIII en su división vestibular; en la modalidad motora somática el XII NC; en la modalidad motora branquial el VII NC y en la modalidad motora parasimpática el VII NC. 
Soto J C; Rojas N S; Téllez G Y; Orozco A M; Sampayo A M; Lizarazo S A. Revista Científica Signos Fónicos, 2019,5(2): 61-96.

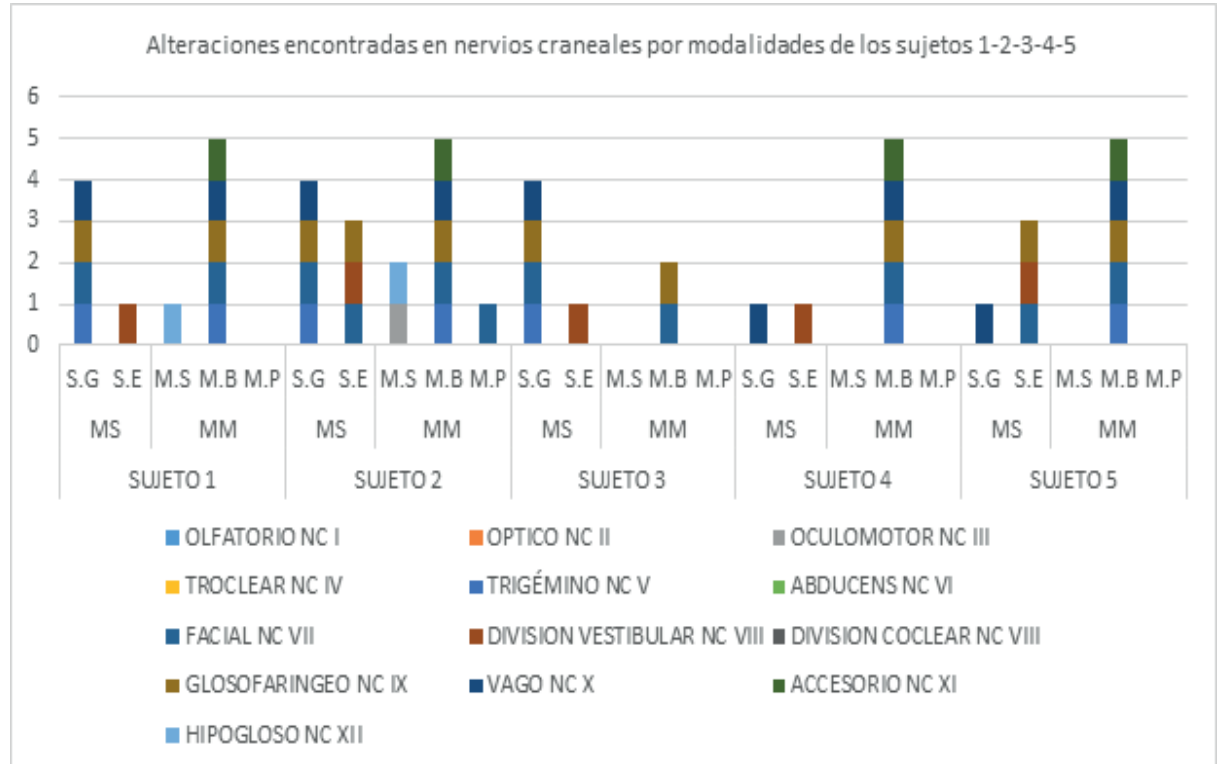

Grafica 28: Alteraciones por modalidades y nervios, sujetos del 1 al 5 . Fuente los autores

Se observa que los nervios con mayor frecuencia de alteración en los sujetos del 6 al 10 dentro de la modalidad sensitiva general son V - VII - IX NC; en la modalidad sensitiva especial el VIII en su división vestibular; en la modalidad motora somática el XII NC; en la modalidad motora branquial son V - VII IX - X NC y en la modalidad motora parasimpática el VII NC.

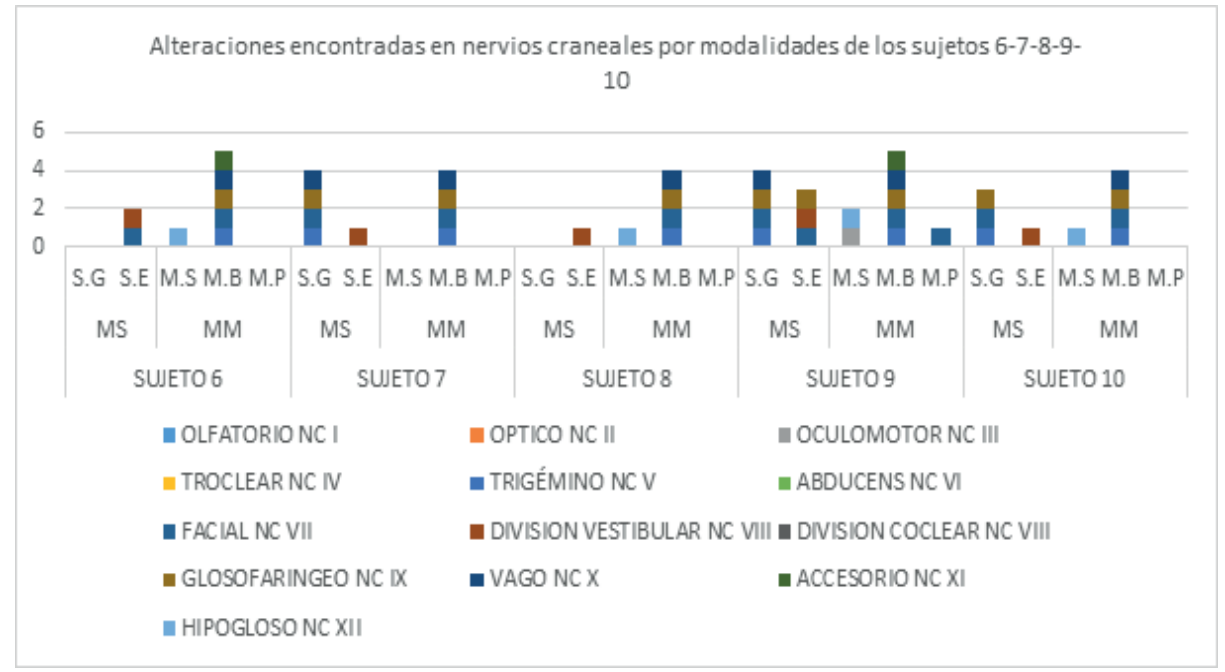

Grafica 29: Alteraciones por modalidades y nervios, sujetos del 6 al 10. Fuente los autores

Se evidencia alteración antes y después de la deglución en los sujetos 5 y 8 mediante la evaluación ausculta cervical bajo los parámetros planteados por el Protocolo Fonoaudiológico de Avaliação do Risco para Disfagia (PARD). 
AUSCULTA CERVICAL - 5ML DE ALIMENTO PASTOSO

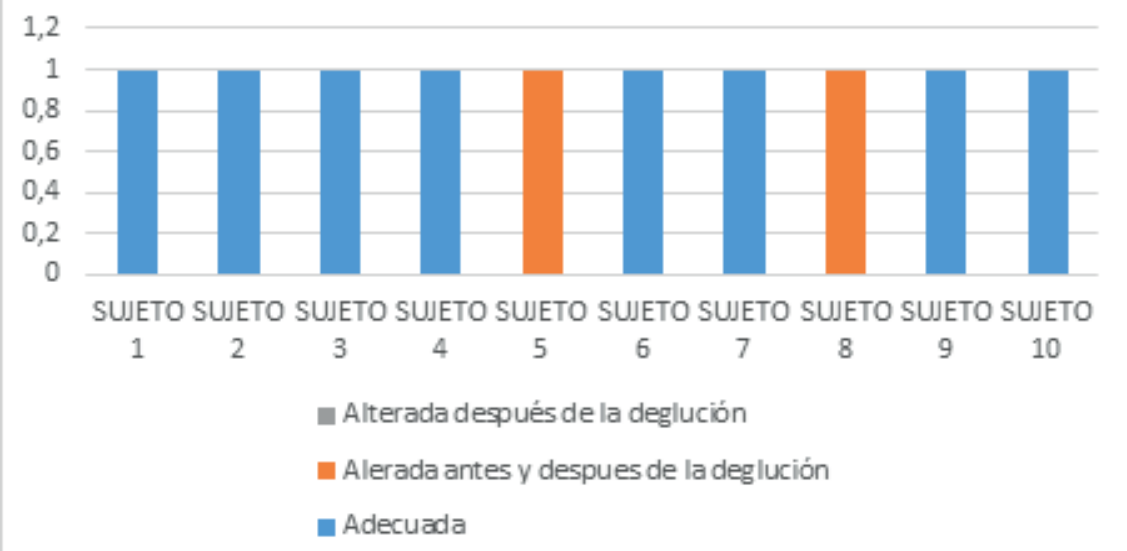

Grafica 30 Resultados de ausculta cervical bajo de los parámetros del protocolo fonoaudiológico de evaluación y riesgo para disfagia PARD. Fuente los autores

\section{ANÁLISIS Y DISCUSIÓN}

El sistema estomatognático es una unidad funcional conformada por estructuras y órganos que actúan en sinergia, la boca y los maxilares, por ejemplo, manteniendo una interrelación recíproca y constante con el resto del organismo, conociendo la importancia se debe realizar una evaluación funcional y estructural de este sistema. (23)

Por tanto, la evidencia aquí documentada en el análisis de las funciones estomatognáticas con el protocolo MBGR, como se pudo observar en resultados los sujetos reportan diagnósticos de base neurológica relacionado con dificultades en el proceso deglución por diferentes causa o razones por ello mismo se dice que : La deglución normal, completa y segura es aquella que en el momento de tragar los labios realizan un contacto sin esfuerzo, la oclusión armónica, la lengua se apoya en el paladar en la zona posterior a los incisivos superiores sin entrar en contacto posterior a esto se realiza el movimiento deglutorio. (24) dejando claro que es un proceso complejo ya que se realiza desde la octava semana de gestación como un reflejo o una respuesta ante un estimulo dado. Esta cuenta con cuatro fases: preparatoria, oral, faríngea y esofágica; reproduciéndose una tras otra. A partir de estructuras en un buen estado y funcionalidad sin interrumpir de manera negativa el proceso de cualquier función estomatognática.

La muestra de la población objeto de investigación reportó cambios anatómicos y funcionales de las regiones facial y oral, probablemente debido a cada una de las patologías de base además se encuentran factores influyentes como la edad y el deterioro cognitivo en el que se encuentran de base. Presentando una disfunción en los procesos de respiración, deglución en algunas consistencias, masticación y estado de la musculatura esquelética. La teoría permite afirmar que la deglución es una función consciente y esencial en el ser humano para cumplir con los requerimientos calóricos y nutritivos necesarios evitando algún tipo de complicación. (25) Claro esta que los usuarios por sus diagnósticos poseen características propias dentro de la patología d base en algunas estructuras utilizadas en cualquiera de las funciones estomatognáticas; es decir complicaciones motoras y sensitivas que no permiten desarrollar estas mismas con un proceso adecuado y coordinado.(26) Por lo mismo cada uno de los usuarios presentan características diferentes a lo largo de la evaluación pero coincidiendo en algunos aspectos; teniendo en cuenta esto se hace vital de tal forma evaluar todas las funciones orofaciales estomatognáticas además del estado de cada una de las estructuras anatómicas sean pasivas (estructuras óseas) o activas ( musculatura, labios, mejillas, lengua) y estructuras anexas (nervios, vasos o glándulas del área) son herramienta fundamental en cada función, sin embargo, existente otros elementos que son determinantes como la estabilidad del tono muscular, la movilidad de los órganos fonoarticulatorios, esenciales para problematizar desde todas las perspectivas el comportamiento del fenómeno. Obteniendo la participación activa en la mayoría del tiempo por parte del usuario. (27)

Los elementos como deglución y masticación se denotan como una secuencia, dado que trabajan en conjunto y el desbalance de uno afecta al otro. Estos se distinguen por presentar una ineficiencia, que se relacionan a movimientos de cabeza, ruidos, la contracción de ciertos músculos y mal posicionamiento lingual. En la literatura se encuentra ampliamente documentado el punto crucial que es

Revista Científica Signos Fónicos, 2019,5(2): 61-96. ISNN 2422-1716. 
Soto J C; Rojas N S; Téllez G Y; Orozco A M; Sampayo A M; Lizarazo S A. Revista Científica Signos Fónicos, 2019,5(2): 61-96.

la lengua para el equilibrio neuromuscular de la región facial y la disfunción en praxias linguales que puede ocasionar el SRO, así mismo, las repercusiones en la deglución y masticación, ya que genera adaptaciones en ellas y el hecho de compartir la misma vía tanto para la respiración y deglución, hace que los alimentos sean rápida e incompletamente masticados y traer como consecuencia problemas digestivos y atragantamientos por la incoordinación de la respiración con la masticación. (28)

El paso de los años produce una serie de cambios anatómicos y fisiológicos que pueden afectar las funciones principales y vitales de nuestro cuerpo, como la deglución, en especial en la cavidad oral donde ocurre la perdida de dentición, el deterioro muscular y la xerostomía o boca seca. En la población se encuentran personas entre en edad adulta donde no han tenido la limpieza necesaria con esta cavidad donde se podría que decir que también es un factor aparte de la edad en este aspecto, además en estas patologías se pueden encontrar torpezas musculares o motoras y sensitivas donde se podría asociar con disfunciones estomatognáticas. (29)

La evaluación por medio del protocolo MBGR evaluación miofuncional orofacial adjunta además un valor agregado por parte del paciente y este es el compromiso o estado de conciencia ya que puede presentarse un tipo de riesgo, ya que este requiere de realizar ordenes sencillas guiadas, por lo tanto algunos ítems de este protocolo no se pueden llevar a cabo en esta población, como lo es Habla, Dolor durante la palpación; por que los usuarios se encuentran medicados o su cognición no permite realizar la comprensión de órdenes. (30) Al mismo tiempo este protocolo nos ayuda a determinar si existe la posibilidad de un trastorno deglutorio donde se encuentra un desorden en el transporte del bolo alimenticio desde la boca hacia el estómago donde no es percibido por el usuario o cuidador, (14) además de esto, los pacientes que poseen una enfermedad neurológica pueden adecuar su alimentación consecuente a sus necesidades por esto mismo vienen a jugar un papel fundamental los hábitos alimentarios la capacidad de autoalimentación, seguridad generando independencia ayudando a mantener un óptimo nivel de salud y calidad de vida (3)

Las dificultades más frecuentes en un trastorno deglutorio con respecto a la deglución normal encontramos; la posición frontal de la lengua desde la fase oral, la contracción de los labios para la impulsión, el escape de alimentos, si el sujeto no puede realizar un selle de la lengua con las arcadas dentarias o compensarlo con acción mentoniano o labial, la falta de contracción de maseteros, contracción del mentón, movimientos del cuido, ruidos al tragar y mantener residuos de alimentos en la boca después de deglutir. (31)

Por esto para la determinación de un trastorno deglutorio se debe comenzar por la evaluación en la presencia del bolo alimenticio, la duración y que tipo de trastorno es, para posterior a esto realizar un examen físico completo con hincapié en el examen otorrinolaringológico, pulmonar y neurológico. Esta evaluación tiende a ser subjetiva e incompleta por la ausencia de protocolos establecidos, el desconocimiento de los factores de riesgo relevantes en la aparición del trastorno de deglución. Aunque se recomienda el uso de exámenes complementarios como: esofagograma con bario, esofagograma contrastado con aire, cintigrama de bolo, ultrasonografía, video fluoroscopia y nasofibroscopía (8)

En la fonoaudiología se ha ido incorporando con mayor fuerza la documentación fotográfica especialmente a nivel de la motricidad orofacial con fines de valoración, desarrollo de razonamiento clínico y seguimiento en la evolución del usuario. (10) La armonía facial ha sido estudiada a través de la historia y muchos autores la proponen como pilar fundamental de la belleza siendo un concepto subjetivo, se puede hacer algo más objetiva gracias a las mediciones antropométricas (32)

En el presente estudio se efectuó el análisis de la antropometría facial en donde se utilizó el registro fotográfico según cattoni y Ricketts mediante la medición fácial vertical, horizontal, ángulos, línea $\mathrm{H}$ Holidaway, ángulo Z merrifield y el biotipo fácial.

El análisis de la antropometría facial es un método moderno de medición, que entrega una reproducción digital fidedigna del sujeto en estudio, que no requiere elementos sofisticados para su desarroIlo(12) Ricketts presentó su análisis cefalométrico en 1960. Procuró desarrollar un sistema de magnitudes que definieran el valor numérico de la tendencia del crecimiento facial, las proporciones dentarias, la posición del mentón y del maxilar y finalmente la estética facial (11) El trabajo de Reed A. Holidaway está basado en el análisis cefalómetro de tejidos blandos y su uso en la planificación de un tratamiento. (33)

De acuerdo con la literatura para realizar un adecuado análisis facial de las alteraciones en las estructuras craneofaciales es muy importante referenciar las fotografías en planos laterales y frontales y de ahí

Revista Científica Signos Fónicos, 2019,5(2): 61-96. ISNN 2422-1716. 
subdividir el rostro humano en proporciones o dimensiones para determinar las asimetrías como las simetrías faciales. La asimetría facial es la condición básica del cuerpo humano y ha estado presente en toda su evolución (34) por consiguiente la simetría es el balance referido al equilibrio facial; es decir, a la correspondencia entre el tamaño, la forma y la ubicación de las características faciales de un lado con respecto al lado opuesto en el plano medio sagital (35)

La población estudiada en esta investigación presenta una prevalencia de alteraciones craneofaciales. En el muestreo, se observó que existen cambios en las estructuras craneofacial como las variaciones proporcionales en la división vertical y horizontal es decir en los quintos y tercios superior, medios e inferior. En el muestreo, se observó que en la división facial vertical el en el quinto 3 donde $40 \%$ de la muestra (n:4) se evidencia que la distancia del canto externo del ojo derecho a interno derecho está aumentad. Muchas de estas asimetrías parecen estar relacionadas con anormalidades durante el desarrollo embriogénico temprano, afectan las vías de migración y la proliferación de las células de la cresta neural, esto puede deberse a síndromes craneofaciales (36) Al observar los resultados arrojados por el estudio, uno de los datos a resaltar es el índice de prevalencia presentes en los ángulo naso- facial y naso-labial, el $70 \%$ de la muestra (n:7) se encuentra en parámetros de normalidad; el $60 \%$ de la población (n: 6) tiene el ángulo nasofacial aumentado y $60 \%(n: 6)$ tiene el ángulo nasolabial disminuido, así mismo se puede evidenciar que el $60 \%$ (n:6) tiene el ángulo naso-facial aumentado y el 10\% (n:1) disminuido, sin embargo el $70 \%$ (n:7) del 100\% de la muestra estudio tiene el ángulo mentocervical normal, es importante destacar que el $100 \%$ de la muestra no tiene disminuido este ángulo; estas asimetrías, en contraste con el ángulo Z merrifield se observó que el $40 \%$ de la muestra ( $n: 4)$ se encuentra en parámetros de normalidad; el análisis de la literatura contribuye que estas asimetrías pueden estar relacionadas no solo con la posición sino también con la morfología asimétrica de la mandíbula. Diferencias en la longitud del cuerpo mandibular, así como también diferencias en la altura de la rama, pueden guiar a una asimetría. El desarrollo de estas asimetrías se inician tempranamente en la vida fetal y continúan a través del que puede resultar de disturbios en el desarrollo posnatal.(37) la imputación dentaria, la ausencia congénita de dientes permanentes, la variación en el tamaño y forma de los dientes y la formación de dientes supernumerarios conllevan a una asimetría facial.

En la línea H Holidaway, se observa que el $50 \%$ de la muestra(n: 5) está alejada de la línea y el $20 \%$ (n:2) traspasa la línea es decir que los labios no están ubicados adecuadamente, el labio inferior está aumentado, sin embargo el $30 \%$ de la muestra (n:3) estudiada presentan la ubicación adecuada de los labios, evidenciándose la posición baja de los labios a consecuencia del tono muscular disminuido. (38) El biotipo facial corresponde a un conjunto de características morfodiferenciales de individuos de la misma especie, en relación a los rasgos en común del esqueleto facial (21) Los resultados obtenidos evidencian valores bastante cercanos al biotipo dólicofacial el $70 \%$ de la muestra $(n: 7)$ presenta este biotipo, pueden presentar mandíbulas con ramas poco desarrolladas en relación al cuerpo, cara alargada, arcadas dentarias angostas. Presentan divergencia entre la mandíbula y la base craneal y entre la base mandibular Predominando el largo sobre el ancho en las dimensiones esqueletales. Su dirección de crecimiento es vertical (21), el $20 \%$ de la muestra ( $n: 2$ ) tiene biotipo braquifacial haciendo referencia a la dirección de crecimiento horizontal estos usuarios presentan mandíbulas con ramas potentes, caras anchas, arcadas dentarias bien desarrolladas, existe un mayor desarrollo muscular, dirección de crecimiento horizontal; éste se manifiesta por una rotación anterior de la sínfisis mandibular y el eje facial tiende a girar hacia adelante y arriba. El mentón es prominente y el surco mentolabial usualmente es marcado (12)

Por otra parte, el registro fotográfico constituye una herramienta de instrumento diagnóstico, por lo tanto, permite preservar todas las características clínicas del paciente y resulta mucho más sencillo y eficaz que una larga descripción verbal. Se puede decir que la fotografía constituye un elemento primordial en el seguimiento de casos clínicos porque aporta información de las condiciones iniciales del paciente, y los cambios que se generan durante el tratamiento.

El sistema estomatognático es una unidad funcional conformada por estructura y órganos que actúan en sinergia, la boca y los maxilares, por ejemplo, mantienen una interrelación recíproca y constante con el resto del organismo. Las funciones estomagtonaticas como la masticación, respiración, deglución y articulación deben ser debidamente valoradas y en cada caso intervenidas. (39)

La evaluación integral de la funciones estomatognáticas, parte de la valoración extraoral pasando por la exploración intraoral normalmente con mecanismo subjetivos, por lo cual se realizó una evaluación estructural intraoral completa, a través del análisis de Pont-Korhaus, El cual es un estudio complementario ortodrómico donde de la longitud del arco dental se compara con el tamaño individual de los

Revista Científica Signos Fónicos, 2019,5(2): 61-96. ISNN 2422-1716. 
dientes para determinar el apiñamiento, las longitudes de la arcada incluyen el perímetro, distancia transversal de caninos a molares y profundidad del paladar. Los resultados obtenidos en el análisis son importantes para establecer lineamientos en el tratamiento y comparar sus efectos; esto último principalmente en la expansión del maxilar. Esta modalidad de tratamiento se (40)

La población de objeto de investigación perteneciente al grupo de usuarios con patologías de base neurológica reportó variación en los anchos en los arcos dentales superiores se encontraron aumentados con respecto a los informes encontrados en la literatura.(41) Específicamente se espera que Las personas que presentan ya sea una mordida abierta, un empuje lingual, tengan un aumento en la longitud del arco superior en sentido anteroposterior más que en sentido transversal como se observa en estos pacientes, este hallazgo contrasta con los estudios realizados en pacientes con daño neurológico en donde la explicación a esta discrepancia puede deberse a la influencia que tienen la lengua sobre la forma de los arcos dentales cuando los pacientes no se encuentran hablando o deglutiendo . Una posición fija de la lengua en el maxilar puede producir una presión contra las caras linguales de los molares superiores.(42)

Sin embargo en un estudio realizado en En Perú, para determinar la aplicación del índice de Pont en mestizos, realizado por Denegri MA permite afirmar que el índice anatómico dentario no necesariamente tiene directa relación en el proceso mecánico de la masticación y la deglución, ya que estas acciones están controladas por el proceso sistémico neuromuscular (43); en el caso de esta investigación se demuestra esta afirmación con la población objeto, en donde se evidencian características particulares de acuerdo a cada diagnostico que compromete la biomecánica de la deglución y sus funciones a nivel funcional y estructural, sobre todo en los procesos de la masticación para la preparación del bolo alimenticio.

En este estudio los investigadores destacaron la importancia de innovar en los procesos de valoración diagnosticas de la cavidad oral dada su relación con el inicio del proceso deglutorio a través de técnicas que han sido utilizadas por otros profesionales y disciplinas, que favorecen la evaluación objetiva, la asertividad en el diagnóstico y una visión más clara para direccionar el eje terapéutico, demostrando que es posible incorporar en la evaluación fonoaudiológica de las funciones estomatognáticas, la valoración anatómica de la cavidad oral, en colaboración con la odontología, que en este caso se encarga del diseño de los modelos dentarios o réplicas de la cavidad oral real de los usuarios y adicionalmente fortalecer el análisis interdisciplinario de la cavidad oral en lo referente a la dentición y al desarrollo del proceso maxilar y palatino.

Existen varios exámenes en la evaluación de la disfagia, dentro de los que podemos encontrar la evaluación clínica, que es un examen para la exploración de las etapas de la deglución, pre-oral, oral y faríngea, dichas etapas evaluadas en velocidad, coordinación y sincronía con diferentes consistencias de alimentos, identificando la probabilidad de presentar alteraciones en la eficacia y seguridad de la deglución con posibles aspiraciones bajo auscultación laríngea, estableciendo así una relación entre posibles dificultades en el proceso deglutorio ya sea aspiración o penetración, a través del estudio de las características presentadas entre ellas una deglución lenta o presencia de tos débil (44) Se han reportado casos en los que esta evaluación puede coincidir con los diagnósticos previos, siendo suficiente para establecer un plan de tratamiento efectivo. Para llevar a cabo de forma adecuada la aplicación de esta prueba, los profesionales deben tener un conocimiento previo del diagnóstico base, el estado neurológico, respiratorio y nutricional que presenta el paciente, además de realizarle una entrevista diagnóstica por medio una serie de preguntas al paciente y a los familiares sobre los signos y síntomas, además del tiempo en que se han evidenciado dificultades para los procesos deglutorios. (45)

Así mismo se tiene en cuenta la inervación correspondiente a cada estructura para realizar la evaluación de la movilidad y tono de la musculatura orofacial, movimientos bucolinguales y reflejos de protección como el tusígeno, que es generado como un mecanismo de defensa ante la penetración de cuerpos extraños en el vestíbulo laríngeo, glotis y tráquea, el reflejo nauseoso que es una reacción de protección que se pone en funcionamiento cuando un estímulo desagradable o externo toca la base de la lengua o el pilar posterior, este busca eliminar de la cavidad oral la sensación, produciendo una contracción involuntaria y brusca del paladar blando y de los constrictores faríngeos. (46)

Para la realización de la evaluación con la sincronía, etapas deglutorias coordinadas y la eficiencia de las válvulas, se deben suministrar alimentos con base a las posibilidades del paciente para manejarlos de acuerdo a la consistencia. Las características que se deben tener en cuenta para realizar la evaluación adecuada del paciente es si su selle labial es adecuado o inadecuado es decir incapacidad de

Revista Científica Signos Fónicos, 2019,5(2): 61-96. ISNN 2422-1716. 
mantener el bolo dentro de la boca, si hay residuos orales una vez finalizada la deglución, además si presenta degluciones sucesivas para limpiar el bolo, si hay sospecha de residuos faríngeos mediante sensación del paciente y auscultación laríngea, o si el paciente presenta regurgitación nasal(23)

Esta exploración clínica durante el proceso de alimentación debe estar acompañada por exámenes complementarios como la pulsoximetría, la cual es utilizada para realizar la evaluación en pacientes con disfagia y permite realizar el monitoreo de la saturación de oxígeno, que es la medición que el oxímetro de pulso administra de forma continua pormedio del sensor en el dedo o en el lóbulo del pabellón auricular (oreja), proporcionando información sobre la absorción de oxígeno en los glóbulos rojos.(47) Esta saturación es definida como el porcentaje de oxigeno arterial en torrente sanguíneo para la medición de la oximetría de pulso durante la deglución. El concepto pulso hace referencia a la medida no invasiva de la saturación de oxigeno $(\mathrm{SpO})$, funcionando mediante el examen transcutáneo del espectro del color de la hemoglobina cambiando con el grado de saturación que se presente, este funcionamiento es dado por el cambio del color entre la sangre venosa y la sangre arterial (rojo brillante). (48)

El uso del oxímetro para detectar el riesgo de aspiración es basada en la disminución de la impregnación respiratoria que causa una disminución en la saturación del oxígeno y es usado con mayor frecuencia en pacientes con inestabilidad clínica, estos niveles se consideran adecuado cuando hay incluso una reducción hasta del $4 \%$ de la línea de base pero inadecuado o caída de la saturación cuando hay una disminución de más del $4 \%$ en la línea de base del paciente. (49)Estas medidas tomadas por medio del oxímetro pueden verse afectadas por diferentes factores como, el movimiento que es la causa más común, sobre todo en niños muy pequeños, o en pacientes con alteraciones de tipo neurológico que poseen movimientos involuntarios, hipersensibilidad o hiperresposividad, debido a que cuando hay movimiento o ruido la amplitud de la óptica se modifica y supera la señal real, por lo que se establece el movimiento como una limitación física para la oximetría de pulso, dado a que el movimiento de la sangre venosa, que el oxímetro de pulso detecta como si fuera sangre arterial pulsátil, durante el movimiento de vaivén de la sangre venosa a baja presión. (50)De acuerdo a lo evidenciado durante la aplicación de esta prueba a los diferentes pacientes es importante decir que no presentaron desaturaciones con relación a la línea de base de cada uno, siendo solo en $4 \%$ y menos de $4 \%$ en la saturación del oxígeno.

La disfagia puede tener distintos grados de severidad y para llevar a cabo esta clasificación se puede hacer uso de instrumentos como la Escala de Ingesta Oral Funcional FOIS (Functional Oral Intake Scale), la cual mide la alteración de la deglución en 7 niveles, en donde el nivel 1 el más severo y el nivel 7 el menos severo o deglución normal. La escala establece cada nivel con características específicas que permitan fácilmente según sus signos y síntomas, el nivel 1 describe nada de alimentación por vía oral, como es caso de los pacientes alimentados por gastrostomía, el nivel 2 establece la dependencia de vía alternativa de alimentación y mínimo consumo de algún alimento sólido o líquido por vía oral, así mismo el nivel 3 presenta la dependencia de vía alternativa de alimentación y consistente consumo de alimentos o líquidos, el nivel 4 muestra sólo la alimentación por vía oral de una única consistencia, en el nivel 5 alimentación por vía oral con múltiples consistencias, pero con necesidad de preparación especial y/o compensaciones, el nivel 6 la alimentación por vía oral con múltiples consistencias, sin necesidad de preparación especial o compensaciones, pero con restricciones alimentarias y el nivel 7 una alimentación por vía oral sin restricciones. (51)

Para realizar la categorización en la escala se deben evaluar las diferentes dificultades en cada fase del proceso deglutorio, como los presentados en la fase preparatoria oral, es decir el cierre labial reducido, dificultades en el movimiento de la lengua para formar el bolo, disminución en la coordinación de los movimientos de la lengua para controlar el bolo, falta de sensibilidad oral, disminución en los movimientos laterales y verticales de la mandíbula, falta de tensión bucal, en la fase oral propulsión de los alimentos fuera de la cavidad oral por la lengua, reducción y desorganización en los movimientos anteroposteriores de la lengua, además de tensión bucal disminuida, en la fase faríngea retardo o ausencia de reflejo deglutorio, inadecuado cierre velofaríngeo, disminución de la peristalsis faríngea, parálisis unilateral de la faringe, disfunción cricofaríngea, así como la reducción en la elevación y cierre laríngeo. (52)Estas diferentes observaciones fueron analizadas durante la investigación con cada uno de los pacientes a los que se le aplicaron cada una de las pruebas, evidenciando alteraciones y procedimientos como crisis convulsivas, cirugías de cabeza y cuello, gastrostomía, hipo e hipersensibilidad ante el toque y toque con presión facial y cavidad oral, disminución en la movilidad del velo del paladar, escape oral, transito oral lento. 
El estudio de la función deglutoria ha ido cobrando cada día mayor trascendencia dado a la importancia de su función y a que las estructuras involucradas en ejecutar las maniobras necesarias para el trasporte del bolo alimenticio desde cavidad oral hasta el estómago requieren de un desarrollo y una coordinación específica que les permita impedir el ingreso de partículas de alimento por vía aérea

La deglución es una de las funciones vitales del organismo y tiene como finalidad permitir la ingesta alimenticia y el aporte nutritivo que el individuo necesita con eficacia y seguridad.(54) Se trata de uno de los procesos más complejos e imprescindibles para el adecuado desarrollo de la vida humana, el cual requiere de la participación de diversas zonas cerebrales y de un preciso control neuromuscular de estructuras relacionadas con cavidad oral, faringe y esófago. La dinámica deglutoria está dividida en cuatro fases descritas por Fishman; la preparatoria oral, encargada de la formación del bolo alimenticio a través de la trituración de los alimentos y la fusión de estos con la saliva; la fase oral, en esta instancia el bolo alimenticio es transportado desde el dorso de la lengua hasta la entrada de la faringe mediante la coordinación de movimientos linguales; la fase faríngea, en la cual se ejecutan funciones de traslado del bolo alimenticio desde la base de la lengua, a través del istmo de las fauces, hasta llegar a la pared faríngea posterior, el estímulo generado por el contacto del bolo contra la mucosa del paladar blando, faringe y epiglotis, activa una serie de reflejos cuya principal función es asegurar que el bolo llegue al esófago sin ingresar a la vía aérea superior ni inferior; la fase esofágica inicia con el paso del bolo por esfínter esofágico superior EES y de manera involuntaria, continua su trayecto hacia el estómago a través movimientos peristálticos. (55) Cuando alguna de estas etapas carece de sincronía, eficacia y coordinación se presenta la disfagia, de ahí que su clasificación esté relacionada directamente con las fases antes descritas como se observa en la tabla 3 y sus grados de severidad se encuentran determinados según el compromiso de las funciones implícitas en el acto deglutorio como se puede apreciar en la tabla 4.

\begin{tabular}{cc} 
Tipo de Disfagia & Alteración \\
\cline { 2 - 3 } Oral preparatoria & $\begin{array}{c}\text { Se caracteriza por la dificultad en el momento de la toma } \\
\text { de alimentos y en poder conformar un bolo alimenticio } \\
\text { adecuado }\end{array}$ \\
De fase oral & $\begin{array}{c}\text { La dificultad se presenta en la manipulación del bolo y en } \\
\text { la propulsión del mismo }\end{array}$ \\
Le faríngea & $\begin{array}{c}\text { La dificultad se presenta en el momento del vaciamiento } \\
\text { faríngeo donde intervienen una serie de reflejos protecto- } \\
\text { res y el RDD }\end{array}$ \\
\hline Tabla 3. : Clasificación de la disfagia (3). Fuente: Los autores \\
gico
\end{tabular}

\begin{tabular}{|c|c|}
\hline Grado de Disfagia & Compromiso \\
\hline Normal & $\begin{array}{l}\text { Masticación y deglución segura, eficiente ante todas las } \\
\text { consistencias de alimentos }\end{array}$ \\
\hline Leve & $\begin{array}{l}\text { Masticación y deglución eficientes ante la mayoría de ali- } \\
\text { mentos, ocasionalmente puede referir dificultad, requiere } \\
\text { del uso de técnicas específicas para lograr una deglución } \\
\text { satisfactoria }\end{array}$ \\
\hline Moderada & $\begin{array}{c}\text { Deglución aceptable con dieta balanceada, pero puede } \\
\text { presentar dificultad con consistencias liquidas y sólidas, } \\
\text { requiere supervisión y tratamiento }\end{array}$ \\
\hline Moderada-Severa & $\begin{array}{l}\text { Paciente cuya ingesta oral no es exitosa, requiere de super- } \\
\text { visión constante y asistencia. Solo puede alimentarse con } \\
\text { terapeuta presente }\end{array}$ \\
\hline Severa & $\begin{array}{l}\text { La nutrición del paciente es por método alternativo no in- } \\
\text { giere alimento por vía oral. }\end{array}$ \\
\hline
\end{tabular}

Tabla 4. Grados de disfagia (4) . Fuente: Los autores. 
La etiología de la disfagia se engloba bajo los términos de disfagia neuromuscular y disfagia neurogénica. La neu $\neg$ romuscular denota algún compromiso en los mecanismos efectores del acto deglutorio por deficiencias en la placa motora o en los músculos de la faringe y a posteriori, del esófago. La neurogénica es el resultado de toda disrupción en los mecanismos neurológicos de la deglución por compromiso del sistema nervioso central y/o sistema nervioso periférico. En el mundo se reporta una incidencia anual de disfagia neurogénica entre 400.000 a 800.000 casos.

La disfagia en pacientes neurológicos tiene un alto grado de importancia debido a que es un síntoma grave que pone en riesgo de desnutrición, deshidratación y complicaciones que pueden causar la muerte del paciente. (56)Teniendo en cuenta de que el síntoma de disfagia se encuentra presente con mayor predominio en enfermedades de base neurológica y que ésta función requiere de un control armónico y preciso a nivel neuromuscular, es imprescindible que dentro de la ruta de evaluación sea contemplado el examen minucioso y funcional de los nervios craneales a través de sus modalidades ya que éstos pasan a comandar todas los procesos sensitivo-motores implicados en la deglución.

Las modalidades que transportan los nervios craneales son seis, tres a nivel sensitivo y tres a nivel motor. Dentro de las modalidades sensitivas se encuentra la modalidad sensitiva general la cual percibe estímulos de tacto, dolor, temperatura, presión, vibración y sensibilidad propioceptiva; modalidad sensitiva especial que da cuenta de sensaciones como olfato, visión, gusto, audición y equilibrio; la modalidad Sensitiva visceral, la cual percibe aferencias de vísceras excepto el dolor. Incluidas en la modalidad motora se encuentran la motora somática que inerva a los músculos que se desarrollan a partir de las somitas; la modalidad Motora branquial que inerva los músculos que se desarrollan a partir de los surcos branquiales; y la modalidad Motora parasimpática que aparte de inervar vísceras, inerva las glándulas y los músculos lisos. (57)

Todos los nervios craneales tienen participación dentro del proceso deglutorio, cierta parte de la literatura revisada indica una fase anticipatoria de la deglución, en la cual describe como el cuerpo se prepara para recibir el alimento por medio de rutas de predominio sensorial donde podemos observar cómo se involucran a la deglución nervios craneales como el olfatorio I NC, óptico II NC, oculomotor III NC, troclear IV NC, abducens VI NC y el auditivo VIII NC en sus dos divisiones. Los nervios que operan de manera más activa dentro del acto deglutorio para las fases preparatorias oral, oral y faríngea son el trigémino V NC, facial VII NC, glosofaríngeo IX NC, vago X NC e hipogloso XII NC.(58) La importancia de una evaluación detallada del complejo neuromuscular que actúa en la deglución nos brinda como terapeutas en el contexto de consultorio la posibilidad de tener una noción más específica en cuanto a la alteración que se pueda estar presentando el paciente desde instancias sensitivo-motoras y nos permite de igual manera, tener una mayor aproximación al momento de emitir una impresión diagnóstica de disfagia, que posteriormente se confirmará con la implementación de un método de evaluación objetivo como lo puede ser la Videofluoroscopia o Videoendoscopia.

Incluida dentro de la evaluación de la disfagia se encuentra la auscultación cervical CA, la cual se puede utilizar como método complementario para las evaluaciones de la alimentación, éste método consiste en escuchar los sonidos de la deglución; debe ser realizada antes, durante y después del acto deglutorio obteniendo información acerca de la presencia o no de residuos en región faríngea y laríngea; para el desarrollo de este examen se posiciona el estetoscopio sobre la parte lateral de la unión laríngea y la tráquea anterior a la arteria carótida.(59)(60)

\section{Auscultación Cervical Manifestación.}

Se caracteriza cuando no hay ruido en la secuencia de ex-

Adecuada halación o inspiración, apnea, tragar ruido y exhalación o inspiración

Alterada antes y después de la deglución

En presencia de ruidos respiratorios antes de tragar y mantenimiento de estos mismos ruidos de frecuencia después de tragar

Alterada después de la deglu- Ruidos no observados previamente y evidenciados desción pués de la deglución

Tabla 5. Variables de auscultación Protocolo Fonoaudiológico de Avaliação do Risco para Disfagia (PARD). Fuente: Los autores. 
Soto J C; Rojas N S; Téllez G Y; Orozco A M; Sampayo A M; Lizarazo S A. Revista Científica Signos Fónicos, 2019,5(2): 61-96.

Este tipo de exámenes como la evaluación de nervios craneales y la auscultación cervical son indispensables dentro de la valoración de la disfagia en consultorio, pues proveen al terapeuta de un grado mayor de seguridad y una aproximación más tangible y más precisa en el momento de generar juicios clínicos para determinar impresiones diagnosticas sobre el síntoma de disfagia.

\section{CONCLUSIONES}

El protocolo MBGR Contiene apartados que no son considerados tan relevantes o no se pueden llevar a cabo en paciente con diagnósticos médicos de base neurológica y/o trastornos de comportamiento como por ejemplo: Movimientos mandibulares y oclusión, habla (espontanea, automática, nominación de figuras, coordinación motriz durante el habla). Además requiere de realizar una adaptación en el apartado de movilidad para que a estos usuarios sea más fácil comprender la orden dada. Por esto se concluye que los apartados con más relevancia dentro del protocolo en el momento de la deglución son; postura corporal, medidas faciales, examen extra oral e intraoral, movilidad, tonicidad y funciones orofaciales.

El análisis antropométrico facial mediante el registro fotográfico es una herramienta fundamental para identificar los cambios que se evidencian en las estructuras craneofaciales aportando información de las condiciones iniciales y los cambios que se generan durante el tratamiento, ayuda al profesional a explicar al paciente de una manera más precisa lo que se va a realizar, permitiendo a su vez dar un adecuado diagnóstico bajo resultados de tipo objetivo.

El método Pont y Korkhaus desarrollado por odontólogos puede tener alcances significativos vinculados con la profesión de fonoaudiología, singularmente en los aspectos de sensibilidad diagnosticas de las estructuras orofaciales y de las funciones estomatognáticas.

La evaluación clínica de la disfagia es un instrumento fundamental para determinar las características biomecánicas deglutorias en pacientes con impresión diagnostica de disfagia.

La deglución va más allá del control faríngeo e incluye una serie de componentes que deben evaluados con rigor, con el fin identificar la presencia de alteraciones en cada una de las fases deglutorias.

La importancia de la continuidad de próximas fases en esta investigación y poder dar como producto un protocolo de atención en evaluación y tratamiento de disfagia en población con dx de base neurológica ya que la mayoría de centros en los que realizamos la practica formativa tienen este tipo de $\mathrm{dx}$ y muchas veces no contamos con herramientas que logren dar realmente una aproximación al dx y poder generar con ello una impresión dx más precisa que solo falte por confirmar el dx de disfagia con un examen objetivo como Videoendoscopia o videofluoroscopía

\section{REFERENCIAS BIBLIOGRÁFICAS}

1. Gil bm, blanco fg, fonseca rg. Disfagia y aspiración. :1-26.

2. Llanesv dlmzdsgpdiemdvevlyp, i. Artículos de revisión deglución anormal: algunas consideraciones sobre este hábito. :1-13.

3. Dalton moreno m. Disfagia y voz. Alteración de la voz como parámetro de evaluación de la seguridad en la deglución y alteraciones de la voz relacionados. Logopedia.mail. 2013;68:1-10.

4. Hernández rocha $m p$, sánchez trocino $b$, de la fuente hernández $j$, villanueva vilchis $m$ del $c$, díaz acevedo ja, vilar pineda $\mathrm{g}$, et al. Análisis de patrones de cierre velofaríngeo en pacientes con labio y paladar hendido. Int j odontostomatol. 2015;9(3):385-91.

5. Gónzalez amigo j. Terapia miofuncional en pacientes con parálisis cerebral. 2015;2014-5. Available from: http://uvadoc.uva.es:80/handle/10324/12146

6. Marco guzmán fn. Evaluacion funcional de la voz [internet]. [cited 2018 dec 7]. Available from: www.vozprofesional.cl

7. Santacruz i. Disfagia. Guías y cascadas mundiales. Guías mundiales la organ mund gastroenterol. 2014;1(1):55-72.

8. Vera m, especiales a.disfagia * [internet]. Vol. 68, an fac med lima. 2007 [cited 2019 jul 21]. Available from: http://www.scielo.org.pe/pdf/afm/v68n3/a12v68n3

9. Chuhuaicura p, giannina álvarez ;, maría ; lezcano f, arias a, fernando ; et al. Patrones de deglución y metodología de evaluación. Una revisión de la literatura swallowing patterns and evaluation me-

Revista Científica Signos Fónicos, 2019,5(2): 61-96. ISNN 2422-1716. 
Soto J C; Rojas N S; Téllez G Y; Orozco A M; Sampayo A M; Lizarazo S A. Revista Científica Signos Fónicos, 2019,5(2): 61-96.

thodology. A review of the literature. Int j odontostomat [internet]. 2018;12(4):388-94. Available from: https://scielo.conicyt.cl/pdf/ijodontos/v12n4/0718-381x-ijodontos-12-04-00388.pdf

10. Capacho eer, cubillos dcs, vera edb, barbosa at, bohorquez ac, sinuco yp. Valor de uso clinico de la fotografia en motricidad orofacial. Rev científica signos fónicos. 2017;2(3).

11. Ribeiro ramires $r$, piccolotto ferreira l, queiroz marchesan $i$, martins cattoni $d$, assumpção de andrada silva $\mathrm{m}$. Medidas faciais antropométricas de adultos segundo tipo facial e sexo adult facial anthropometric measurements according to facial type and gender. (1).

12. Rossana r, leslie r, ferreira $p$, queiroz $i$, martins $d$, marta $c$, et al. Medidas de facial tipo facial segundo adulto antropométricas y sexo medidas antropométricas faciales adultos acuerdo de tipo facial y género. (5).

13. Cerda-peralta b, schulz-rosales $r$, lópez-garrido j, romo-ormazabal f. Parámetros cefalométricos para determinar biotipo facial en adultos chilenos. Rev clínica periodoncia, implantol y rehabil oral. 2019;12(1):8-11.

14. Carrera vidal c, larrucea verdugo c, galaz valdés c. Detección de incrementos de dimensión vertical oclusal mediante análisis cefalométrico de ricketts. Rev clínica periodoncia, implantol y rehabil oral. 2010;3(2):79-85.

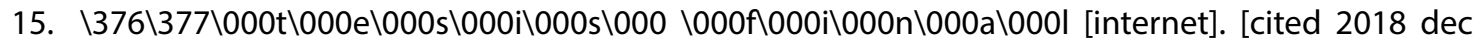

7]. Available from: http://repositoriodigital.uns.edu.ar/bitstream/123456789/2303/1/tesis_conte-grand_2012.pdf

16. De las casas battifora rm, ramada. Functional dysphonia and benign vocal cord lesions in professional voice users. Arch prev riesgos labor. 2012;15(1):21-6.

17. Laura quantin $d$. Malformaciones congénitas de la faringe congenital malformations of pharynx [internet]. [cited 2018 dec 2]. Available from: http://www.faso.org.ar/revistas/2014/2/3.pdf

18. Nacional de la otros trastornos de la deglucioni. Nidcd... mejorando la vida de personas que tienen trastornos de I1. Nacional de la sordera otros trastornos de la comunicación i. Nidcd... mejorando la vida de personas que tienen trastornos de la comunicación departamento de salud y servicios humanos de los [internet]. [cited 2018 nov 29]. Available from: www.nidcd.nih.gov/health/voice/pages/ spasdysp.aspx.

19. Protocolo de evaluación del trastorno deglutorio en adultos. 2018;

20. Menezes e da c, santos fah, alves fl. Cerebral palsy dysphagia: a systematic review. Rev cefac. 2017;19(4):565-74.

21. Villanueva-bonilla s, saavedra-layera l, vergara-núñez c. Comparación de mediciones antropométricas directa y con sistema de imagen $3 \mathrm{~d}$, en adultos jóvenes. Rev clínica periodoncia, implantol y rehabil oral. 2018;11(1):16-9.

22. Cedeño jb. La cara, sus pr opor ciones estéticas. Clínica cent "cira garcía", la habana cuba [internet]. 2015;1-11. Available from: http://www.sld.cu/galerias/pdf/sitios/protesis/la_cara,_sus_proporciones_ esteticas.pdf

23. Moya mp. Lactancia materna y su contribución al adecuado desarrollo del sistema estomatognático y sus funciones. Rev científica signos fónicos [internet]. 2015 nov 11;1(2).

24. Garcia mv, melo pah, guerrero dff, claro akp. Línea funcional como herramienta de screening para la evaluación de la deglución en líquidos. Rev científica signos fónicos [internet]. 2016 apr 1;2(1).

25. Navia hjr, capacho eer, reyes gvp. Análisis discursivo de la motricidad orofacial en colombia. Rev científica signos fónicos [internet]. 2015 jan 30;1(1).

26. Crespo n, rivera e, figueroa f, chacón k, lópez l, gonzalez s. Métodos de evaluación de la voz en docentes una revisión sistemática. Rev científica signos fónicos [internet]. 2018 jun 7;3(1).

27. Cañas sja, redondo al, nieto ápa, portilla emp, rangel rle. Metodologia: tamiz auditivo neonatal. Rev científica signos fónicos [internet]. 2017 oct 25;2(3).

28. Suárez escudero jc, rueda vallejo zv, orozco af. Disfagia y neurología: ¿una unión indefectible? Acta neurológica colomb. 2018;34(1):92-100.

29. El uso profesional de la voz i cat i cast i [internet]. [cited 2018 nov 25]. Available from: http:// treball.gencat.cat/web/.content/09_-_seguretat_i_salut_laboral/publicacions/imatges/us_professional_veu_cast.pdf

30. Gallego cam, redondo al, cabeza jam, gil dmd, carvajal smy, clavijo za, et al. Discapacidad: una

Revista Científica Signos Fónicos, 2019,5(2): 61-96. ISNN 2422-1716. 
Soto J C; Rojas N S; Téllez G Y; Orozco A M; Sampayo A M; Lizarazo S A. Revista Científica Signos Fónicos, 2019,5(2): 61-96.

perspectiva desde los ejes de desigualdad. Rev científica signos fónicos [internet]. 2017 oct 25;2(3).

31. Gázquez linares jj, pérez fuentes $m$ del $c$, molero jurado $m$ del $m$, simón $m$ del $m$, martos á, barragán ab, et al. Conocimientos, investigación y prácticas en el campo de la salud [internet]. Conocimientos, investigación y prácticas en el campo de la salud: volumen iii, 2018, isbn 978-84-09-04244-9, págs. 307-316. 2018. 307-316 p. Available from: https://0-dialnet-unirioja-es.cataleg.uoc.edu/servlet/ articulo?codigo $=6820462$

32. Huentequeo-molina $c$, navarro $\mathrm{p}$, vásquez $\mathrm{b}$, olate $\mathrm{s}$. Análisis facial, dentario y radiográfico de la normalidad facial. Estudio piloto en 29 mujeres. Int j morphol. 2013;31(1):150-5.

33. Universidad central del ecuador carrera de odontología " d iámetro transversal , longitud anterior de las arcadas y medidas antropométricas faciales en edades de 12 a 17 años en una población indígena de otavalo." 2019;

34. Colón peña f. La fotografía como documento social en la construcción de la memoria visual de la sociedad [internet]. Universidad de la salle; 2017 [cited 2019 jul 21]. Available from: http://repository. lasalle.edu.co/bitstream/handle/10185/22378/33091257_2017.pdf?sequence=1

35. Gastaminza f del v. El análisis documental de la fotografía. Cuad doc multimed [internet]. 1993 [cited 2019 jul 21];2:33-43. Available from: https://revistas.ucm.es/index.php/cdmu/article/view/59340

36. Orenga caleri s. ¿la fotografía espejo de la historia?: análisis comparado de las dictaduras y transiciones en brasil y españa (1939-1985) [internet]. Uam. Departamento de historia contemporánea. Universidad autónoma de madrid; 2015 [cited 2019 jul 21]. Available from: https://repositorio.uam.es/ handle/10486/666755

37. Barrios, milena m. Obturar para participar: la fotografía como herramienta para comprender el valor patrimonial del centro histórico de barranquilla. Investig desarro [internet]. 2010 [cited 2019 jul 21];18(1). Available from: http://rcientificas.uninorte.edu.co/index.php/investigacion/article/viewarticle/970/4592

38. Gisèle freund. La fotografía como documento social. In: 2nd ed. Barcelona; 2017 [cited 2019 jul 21 ]. P. 23. Available from: www.ggili.com.mx

39. Noguero fl. El análisis de contenido como método de investigación. Rev educ [internet]. 2002 [cited 2019 jul 21];4:167-79. Available from: http://rabida.uhu.es/dspace/bitstream/handle/10272/1912/ b15150434.pdf?sequence1

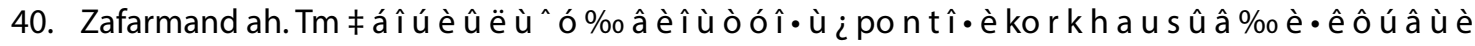
îô “ $\square$ ïëi ûìô ₹mortezaorboubazary 1, ahamidzafarmand2, alimadami3,a t o u s a or b o u b a zary 4 c. 2015;(january 2007).

41. De luis da, izaola o, de la fuente $b$, muñoz-calero $p$, franco-lopez $a$. Enfermedades neurodegenerativas; aspectos nutricionales. Nutr hosp. 2015;32(2):946-51.

42. Cuba rivas reyes $h$, rivas $b$, valdés 0 . Revista habanera de ciencias médicas [internet]. Vol. 12, revista habanera de ciencias médicas. 2013 [cited 2018 nov 29]. Available from: http://www.redalyc.org/articulo.oa?id=180429229010

43. Patino-hernandez $\mathrm{d}$, borda $\mathrm{mg}$, venegas sanabria lc, chavarro-carvajal da, cano-gutiérrez ca. Disfagia sarcopénica. Rev colomb gastroenterol. 2016;31(4):418-23.

44. Redondo al, gallego cam, florez Ilp, machuca ygc, mejia klh, jerez lvm, et al. Relacion entre la discapacidad y la desigualdad de la clase social. Rev científica signos fónicos [internet]. 2017 oct 25;2(3).

45. Cardoso mc de af, silva amt da. Oximetria de pulso: alternativa instrumental na avaliação clínica junto ao leito para a disfagia. Arq int otorrinolaringol. 2010;14(2):231-8.

46. Taveira kvm, santos rs, leão blc de, stechman neto j, pernambuco l, silva lk da, et al. Diagnostic validity of methods for assessment of swallowing sounds: a systematic review. Braz $j$ otorhinolaryngol [internet]. 2018;84(5):638-52. Available from: https://doi.org/10.1016/j.bjorl.2017.12.008

47. Andrade pa, santos ca dos, firmino hh, rosa $\mathrm{c}$ de ob. The importance of dysphagia screening and nutritional assessment in hospitalized patients. Einstein (sao paulo). 2018;16(2):eao4189.

48. Martins s, oliveira d. Correlation between the degree of neurogenic oropharyngeal dysphagia with the level of dysphonia in the elderly: analysis related. Rev pesqui cuid é fundam online. 2014;6(3):1191201.

49. Cubillo b, juan b, smith b, análisis p, utilizados c, el p. Artículo_redalyc_324227905005. 2006;

50. Barrreto-munévar dp, cháux-ramos om, estrada-rangel ma, sánchez-morales j, moreno-angarita

Revista Científica Signos Fónicos, 2019,5(2): 61-96. ISNN 2422-1716. 
$\mathrm{m}$, camargo-mendoza $\mathrm{m}$. Environmental factors and vocal habits regarding pre-school teachers and functionaries suffering voice disorders [internet]. Vol. 13. 2011 [cited 2018 nov 27]. Available from: http://www.scielo.org.co/pdf/rsap/v13n3/v13n3a04.pdf

51. Silva rg da. A eficácia da reabilitação em disfagia orofaríngea. Pró-fono rev atualização científica. 2007;19(1):123-30.

52. Gallego cam, parada ypj, nieto apa, brito yr, redondo al, ascanio j, et al. Determinantes sociales en salud: construccion de conocimiento a traves de la cartografia social. Rev científica signos fónicos [internet]. 2015 oct 1;1(3).

53. Niehaus quesada• hw. Anomalías congénitas de la laringe [internet]. 1977 [cited 2018 dec 2]. Available from: http://www.binasss.sa.cr/revistas/rmcc/rmedica/460/art6.pdf

54. Fazio s, ortega ag, sáenz a. Rmu revision fazio. [cited 2018 dec 3]; available from: http://bdigital. uncu.edu.ar/objetos_digitales/5876/03rmurevisionfazio.pdf

55. Rojas $\mathrm{m}$, reina rueda $\mathrm{cm}$. Habilidades motoras en el desempeño académico en estudiantes del tercer grado nivel primaria de la escuela normal superior cristo rey, santander. Colombia [internet]. 2016 [cited 2019 nov 22]. Available from: https://www.if.ufrgs.br/ moreira/apsigsubesp.pdf

56. Larrouy-maestri $p$, morsomme d. The effects of stress on singing voice accuracy. J voice [internet]. 2014 jan 1 [cited 2018 nov 25];28(1):52-8. Available from: https://www.sciencedirect.com/science/article/pii/s0892199713001446

57. López ell. Revista de antropología experimental. [internet]. Antropología experimental. 2005 [cited 2019 jul 21]. Available from: https://revistaselectronicas.ujaen.es/index.php/rae/article/view/2068 58. Aldunate r. M. Malformaciones pulmonares congénitas. Rev chil pediatría [internet]. 2001 jan [cited $2018 \mathrm{dec}$ 2];72(1):52-7. Available from: http://www.scielo.cl/scielo.php?script=sci_arttext\&pi$d=s 0370-41062001000100010 \& \operatorname{lng}=e n \& n r m=i s o \& t \operatorname{lng}=e n$

59. Elvira mendoza lara d, juana muñoz lópez d. Tesis doctoral presentada para la obtención del título de doctor por marina garzón garcía bajo la dirección de [internet]. [cited 2018 nov 29]. Available from: http://hdl.handle.net/10481/44588

60. Gisèle freund [internet]. [cited 2019 jul 21]. Available from: www.ggili.com.mx 